Title: Improved Tubulars for Better Economics in Deep Gas Well Drilling using Microwave Technology

\title{
Final Technical Report
}

Reporting Period: 10/1/2003 through 7/30/2007

\section{Principal Authors}

Dinesh Agrawal

Professor of Materials, and

Director of Microwave Processing

and Engineering Center

207 Materials Research Laboratory

The Pennsylvania State University

University Park, PA 16802

Phone: (814)-863-8034

Fax: (814)-863-3617

Email: dxa4@psu.edu

Date Issued: October, 2007

DOE Award No. DE-FC26-02NT41662

\section{Submitting Organization:}

The Pennsylvania State University

Materials Research Institute

University Park, PA 16802

\section{Subcontractor/Participant:}

Dennis Tool Company

2020 Rankin Road

Houston, Texas 77073-5100
Drs. Paul Gigl, Mark Hunt and Mahlon Dennis

Dennis Tool Company

2020 Rankin Road

Houston, Texas 77073-5100

281-821-9495 


\section{DISCLAIMER:}

“This report was prepared as an account of work sponsored by an agency of the United States Government. Neither the United States Government nor any agency thereof, nor any of their employees, makes any warranty, express or implied, or assumes any legal liability or responsibility for the accuracy, completeness, or usefulness of any information, apparatus, product, or process disclosed, or represents that its use would not infringe privately owned rights. Reference herein to any specific commercial product, process, or service by trade name, trademark, manufacturer, or otherwise does not necessarily constitute or imply its endorsement, recommendation, or favoring by the United States Government or any agency thereof. The views and opinions of authors expressed herein do not necessarily state or reflect those of the United States Government or any agency thereof." 


\section{Table of Contents}

List of Figures $\quad 4$

List of Tables $\quad 4$

Executive Summary $\quad 5$

$\begin{array}{ll}\text { I. Abstract } & 7\end{array}$

$\begin{array}{lr}\text { II. Experimental } & 8\end{array}$

1. Modification of Microwave System 8

2. Continuous microwave sintering system for trial samples $\quad 8$

3. Fabrication of long tubular samples by CIP 11

4. Bonding of sintered rods using microwave heating 13

5. Mechanical Properties Testing 15

5.1 Torsion test 15

$\begin{array}{ll}5.2 \text { Crush Test } & 16\end{array}$

5.3 Microhardness Test 16

5.4 Corrosion test 16

5.5 Fatigue test 16

6. Fabrication of test samples 17

III. Results and Discussion $\quad 22$

Torsion test 22

Crush Test 23

Microhardness Test $\quad 23$

$\begin{array}{ll}\text { Corrosion test } & 24\end{array}$

$\begin{array}{ll}\text { Fatigue test } & 24\end{array}$

IV. Conclusions and Recommendations 34 


\section{List of Figures}

Figure 3.1. Continuous Microwave system modified to sinter powder metal tubular parts Figure 3.2. Arrangement of samples loading for continuous sintering of cylindrical samples

Figure 3.3. Green CIPed sample (left) and microwave sintered at 1250C/15 min (right).

Figure 3.4. CIP unit from American Isostatic Press Co. used for making green tubes.

Figure 3.5. Tensile Stress data (stress and extension) of bonded sample using 50:50 Fe:Ni.

Figure 3.6. Tensile Stress data (stress and extension) of bonded sample using Co.

Figure 3.7. Tensile Stress data (stress and extension) of bonded sample using 58:42 Fe:Ni

Figure 3.8. Torque test performed on the sample: Samples in torque machine: A. without safety shield, and B. with safety shield.

Figure 3.9. Torsion test samples before test

Figure 3.10. Microhardness photographs

Figure 3.11. Sample in fatigue machine

Figure 3.12. in the fatigue machine after testing at different magnifications.

Figure 4.1. Torsion test samples after test

Figure 4.2. Sample T1 after test

Figure 4.3. Sample T2 after test

Figure 4.4. Failure torque test results

Figure 4.5. Compression test samples

Figure 4.6. Compression sample in load frame

Figure 4.7. Crush test load displacement curves

Figure 4.8. Crush test samples after the test, Sample C1 (left) did not crack. Samples C2, C3, and C4 (right) cracked

Figure 4.9. Crush test samples after the test, Sample C1 (left) did not crack. Samples C2, C3, and C4 (right) cracked.

Figure 4.10. Microhardness photographs

Figure 4.11. Samples used for corrosion test

Figure 4.12. Fatigue failure surfaces ( 0.9 " from right edge of turned down region)

Figure 4.13. Sintered stainless tube fatigue results

\section{List of Tables}

Table 1. Fatigue test strain ranges

Table 2. Equivalent fatigue results. 


\section{Executive Summary}

The objective of the research program has been to improve the rate-of-penetration in deep hostile environments by improving the life cycle and performance of coiled-tubing, an important component of a deep well drilling system for oil and gas exploration. The current process of the manufacture long tubular steel products consists of shaping the tube from flat strip, welding the seam and sections into lengths that can be miles long, and coiling onto reels. However, the welds, that are a weak point, now limit the performance of the coil tubing. This is not only from a toughness standpoint but also from a corrosion standpoint. By utilizing the latest developments in the sintering of materials with microwave energy and powder metal extrusion technology for the manufacture of seamless coiled tubing and other tubular products, these problems can be eliminated. The main objective of the project is therefore to develop a continuous microwave process to sinter continuously steel tubulars and butt-join them using microwave/induction process. The program started about four years ago on October 1, 2003.

In the Phase I a feasibility study of the extrusion process of steel powder and continuously sinter the extruded tubing was conducted. The research program has been based on the development of microwave technology to process tubular specimens of powder metals, especially steels. The existing microwave systems at the Materials Research Laboratory (MRL) and Dennis Tool Company (DTC) were suitably modified to process successfully tubular small specimens. The precursor powder metals were either extruded or cold isostatically pressed (CIP) to form tubular specimens. After conducting an extensive and systematic investigation of extrusion process for producing long tubes, it was determined that there were several difficulties in adopting extrusion process and it cannot be economically used for producing thousands of feet long green tubing. Therefore, in the Phase II the approach was modified to the microwave sintering combined with Cold Isostatic Press (CIP) and joining (by induction or microwave) the tubular parts into long coiled-tubing. Eventually, this process could be developed into a semi-continuous sintering process if the CIP can produce parts fast enough to match the microwave sintering rates. When the program ended the sintering and joining of several tubular parts was completed for conducting third party tests at Stress Engineering. This report summarizes the work of the entire program.

In the Phase II of the program, the steel composition used was 316L since the composition matching with the Quality tubing's QT-16Cr80 was not available in the market in the pre-alloyed powder form. The pre-mixed composition closely matching with QT-16Cr80 caused problems during sintering. Bonding experiments using 4 different braze powders were conducted and the process optimized to obtain high degree of bonding strength. For fabrication of green tubulars a large CIP unit was acquired and used for making up to 18 inch long green tubes. Microwave sintering experiments for continuous processing of the CIPed tubes completed and the samples were joined at Dennis Tool for third party testing at Stress Engineeringwho performed torsion, hardness, corrosion, crush, and fatigue tests on 3/4" OD x $1 / 8$ " wall sintered stainless tubes. The summary of these test is as the following:

Torsion Tests: Two brazed tubing assemblies (sintered stainless steel) were loaded in torsion to failure. The torque turn results from the two tests. Both samples started to yield at the same torque, however, the failure torque and rotation of sample T1 was much higher than sample T2. Both samples failed in the tube near the brazed joint. The results follow:

At yield: Samples T1 and T2 Torque at start of yield $=220 \mathrm{ft}-1 \mathrm{~b}$ Shear Stress $=\tau=36,480 \mathrm{psi}$

At failure: Sample T1 Torque at failure $=393.8 \mathrm{ft}-1 \mathrm{~b} \tau=65,300 \mathrm{psi}$ 
Sample T2 Torque at failure $=273.3 \mathrm{ft}-\mathrm{lb}$ Shear Stress $=\tau=45,320 \mathrm{psi}$

Crush Tests: Four 3" long samples were crushed radially (laying flat on their side) recording the load and displacement. The tubing was visually examined for cracking after being crushed. Samples C2, C3, and $\mathrm{C} 4$ cracked as they were loaded to 23.6 kips. Sample C1 was crushed flat at a load of 61.1 kips and it did not crack.

Micro-hardness Tests: Micro-hardness values were obtained on the OD of two samples. Values were obtained at six locations on either side and in the brazed joints. The samples were mounted, polished, prior to taking the readings.

Corrosion Tests: Corrosion tests were performed in an autoclave at $250^{\circ} \mathrm{F}$ and 500 psi for 96 hours with carbon dioxide bubbled through a $5 \%$ sodium chloride solution to provide $100 \%$ saturation of the brine. Test procedures from ASTM G31 and G111 were used as a guide.

Fatigue Tests: A fatigue test was performed on one sample using SES's resonant fatigue machine. The resonant fatigue machine consists of two supports, a variable speed electric motor, drive housing, and dead weight housing. The variable speed motor rotates an eccentric mass in the drive housing clamped to one end of the sample and loads the pipe. The rpm of the motor is adjusted to load the sample near its natural frequency. The dead weight housing is clamped to the other end of the sample to balance the assembly. The sample failed in the turned down region of the sample after 22.16 million cycles at a stress range of $25.89 \mathrm{ksi}$. Figure 2 shows that the fatigue performance of the sample was comparable to girth welded 57mm OD Super Duplex A670 tubing.

The test results at the Stress Engineering can be summarized as the following:

- Some mechanical properties of the microwave processed tubes were better than the existing tubular, and some were just marginally better or a little inferior.

- The corrosion data in the Stress Eng. report suggests that the microwave sintered performed better than QT-900 and 13\%Cr tubing material, but not as good as QT-16Cr.

- The crush results compare very well against previous microwave samples tested in the QT report from 2004, and performed quite satisfactorily. Some crushed samples became totally flat without showing any cracks.

Based on the test results at the completion of the program, it is concluded that:

- Scale up and sintering of a thin wall common O.D. size tubing that is widely used in the market is still to be proved

- Further experimentation and refinement of the sintering process is needed to entice industry commitment, for example:

- Improved material characteristics would likely be required

- Improved consistency of material characteristics

- Actual manufacturing capability of microwave sintered, industrial quality, full length tubing will most likely require several million dollars of investment. 


\section{Abstract}

The main objective of the entire research program has been to improve the rate-ofpenetration in deep hostile environments by improving the life cycle and performance of coiled-tubing, an important component of a deep well drilling system for oil and gas exploration, by utilizing the latest developments in the microwave materials technology.

Based on the results of the Phase I and insurmountable difficulties faced in the extrusion and de-waxing processes, the approach of achieving the goals of the program was slightly changed in the Phase II in which an approach of microwave sintering combined with Cold Isostatic Press (CIP) and joining (by induction or microwave) has been adopted. This process can be developed into a semicontinuous sintering process if the CIP can produce parts fast enough to match the microwave sintering rates.

The main objective of the Phase II research program is to demonstrate the potential to economically manufacture microwave processed coiled tubing with improved performance for extended useful life under hostile coiled tubing drilling conditions.

After the completion of the Phase II, it is concluded that scale up and sintering of a thin wall common O.D. size tubing that is widely used in the market is still to be proved and further experimentation and refinement of the sintering process is needed in Phase III. Actual manufacturing capability of microwave sintered, industrial quality, full length tubing will most likely require several million dollars of investment. 


\section{Experimental}

The entire research program has been based on the development of microwave technology to process tubular specimens of powder metals, especially steels. In the reporting period the main focus was on selection of steel powder, preparation of green samples by CIP (cold isostatic pressing), microwave processing of test samples and bonding of sintered rods. The existing microwave sintering systems at Materials Research Lab and Dennis Tool Company were suitably modified to process the new steel powders. Also bonding experiments were conducted and preliminary strength data acquired on the bonded samples. The bonded samples were evaluated at the Stress Engineering for hardness, corrosion behavior, fatigue test, crush test and torsion test. Here below are the various experimental procedures for various stages of the tubular samples made and tested under this program.

1. Modification of Microwave system: The existing vertical continuous microwave system at Materials Research Institute (MRI) has been used in the past for the processing of ceramics and WC/Co parts. To process powder metal (steel) samples the systems at MRI and Dennis Tool Company (DTC) were suitably modified by designing and installation of new insulation packages and tube assembly, etc. As the experiments were continued to be executed further modifications were required, for example the original stationary alumina tube was replaced by a larger diameter tube and the associated assembly, to facilitate the smooth movement of crucibles and long steel tubes of diameter $>1.5$ inch. Also some necessary modifications were made in the insulation package and microwave cavity assembly. Several brass tubes were built, joined and installed in the cavity in order to load many powder metal cylindrical samples at the same time. A photograph of this modified continuous microwave system for laboratory type experiments is shown in Figure 3.1.

2. Continuous Microwave Sintering of Trial Samples: First, in order to develop a continuous microwave sintering of steel samples in the new modified microwave system, twelve FN208 (Fe:97.2, Ni:2.0,C:0.8) cylindrical samples ( 1 inch diameter and inch height) were loaded in the microwave furnace for vertically continuous sintering. The arrangement of this approach is schematically shown in Figure 3.2. 


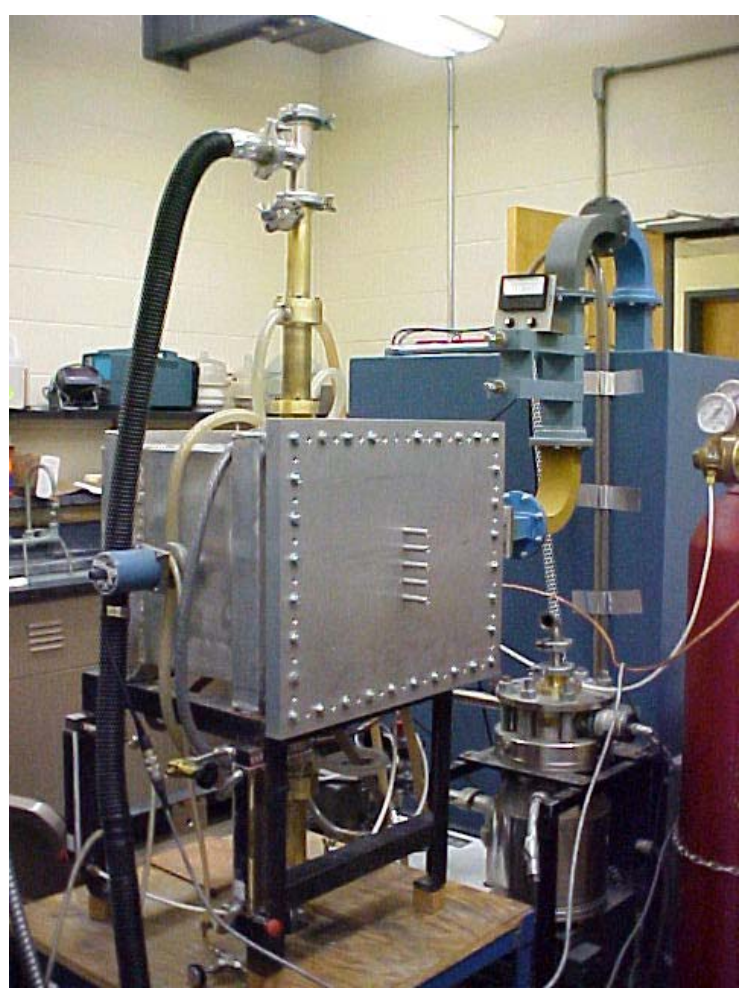

Figure 3.1. Continuous Microwave System modified to sinter Powder Metal Tubular Parts

The processing conditions were adjusted to obtain the optimum sintering temperature of $1250^{\circ} \mathrm{C}$ for processing of FN208, at the center of the cavity. The assembly of the samples was allowed to move vertically downwards with a specific feeding rate. It was found that the softening of the bottom sample at $1250^{\circ} \mathrm{C}$ and the heavy load of the top samples, caused some distortion in the shape of the sintered sample. Otherwise the samples were found to be good after sintering. So, next this experiment was repeated using alumina crucibles to separate the FN208 samples. The ceramic crucibles having much higher strength at high temperatures supported the weight of the steel samples individually. The continuous sintering of cylindrical samples was successfully accomplished with consistent and uniform sintering results. The sintering conditions used were:

Atmosphere: Forming gas $\left(95 \% \mathrm{~N}_{2}+5 \% \mathrm{H}_{2}\right)$, Temperature: $1250^{\circ} \mathrm{C}$, Soaking time: $5 \mathrm{~min}$. Feed rate: $0.2 \% / \mathrm{min}$, Total time to sinter 11 samples: $65 \mathrm{~min}$.

Table 6 lists sintered density data of FN208 trial samples. It is quite clear that all samples have been sintered quite uniformly with very consistent sinter density. 


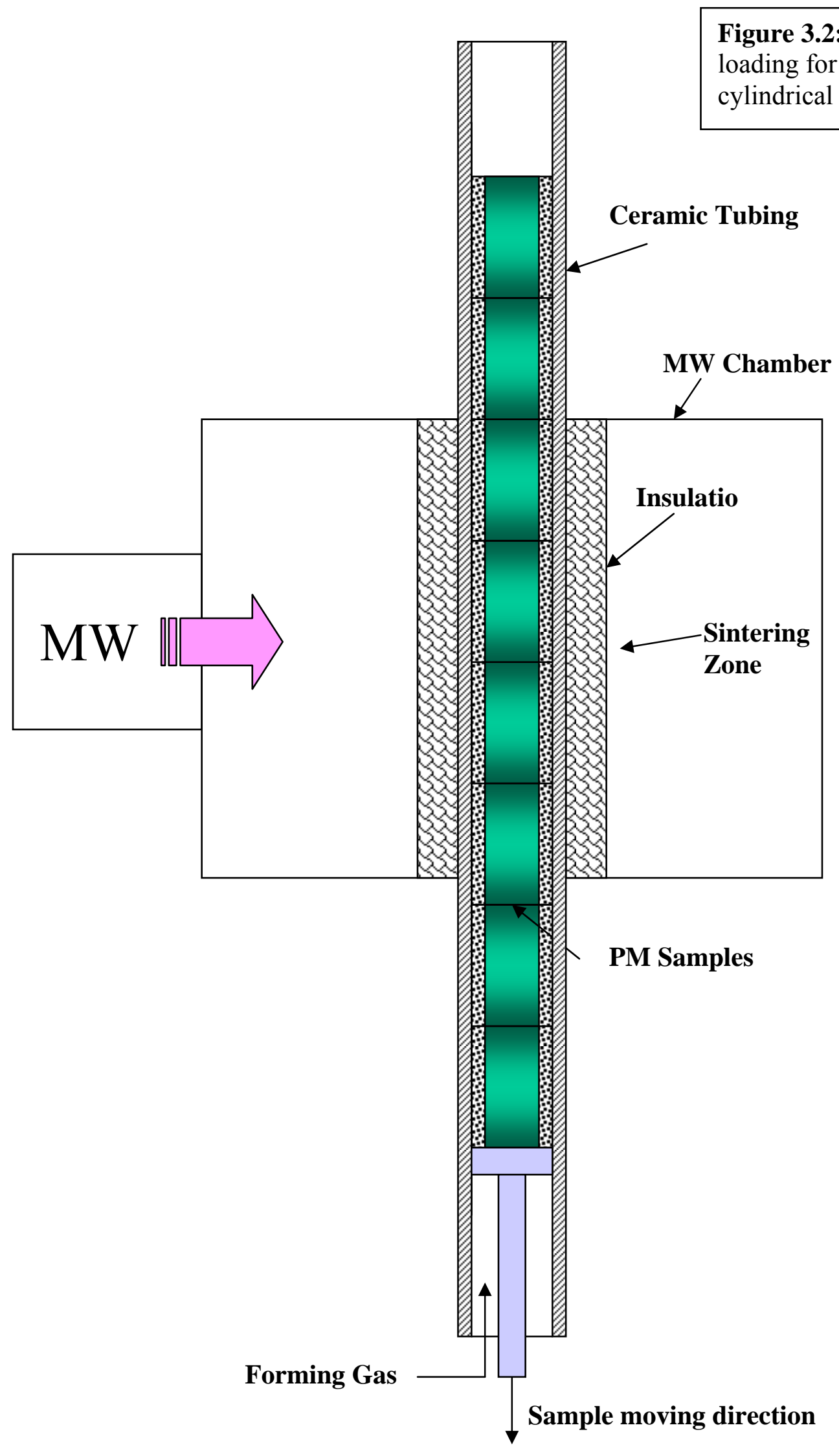


3. Fabrication of long tubular samples by Cold Isostatical Pressing (CIP): For fabrication of long tubular specimens both extrusion and CIP methods were adopted. CIP is a standard method for consolidation of powders by pressing uniformly in all directions. In this method uniform pressure in all sides is applied using a liquid medium and rubber bag containing the powder, providing isostatic conditions. In the extrusion method slurries of the powders are used, and subjected to push through a cavity of desired diameter providing solid/hollow tubular specimens. CIP can produce tubular samples only up to a limited length (1-2 feet). CIP was used to make 12 inch long solid and hollow tubes of nominally 1-1.5 inch diameter. Figure 3.3 exhibits small CIPed green and mw sintered samples. Since CIP processing has been defined as the method for manufacturing the green samples. Two types of CIP equipment are available. Wet bag and dry bag units could be applied to this project. Dry bag is usually automated and done when large numbers of parts are needed. This would be considered for the final production equipment but would be very costly and time consuming for this stage of the development. Consequently, wet bag was considered for our work for now. New machines were two to three times as expensive as the used ones, so the latter is being looked at first. We tested a small CIP machine (4" ID, 18" long, 60,000 psi) at Flow Autoclave (Columbus, Ohio) and American Isostatic Press (AIP), both located in Columbus, Ohio and testing their equipment and considering the price etc. finally a refurbished large CIP system from AIP (Figure 3.4) was purchased and used in this study. This unit was installed at Dennis Tool in Houston and test samples were prepared there and then sintered at Penn State in the continuous microwave system.

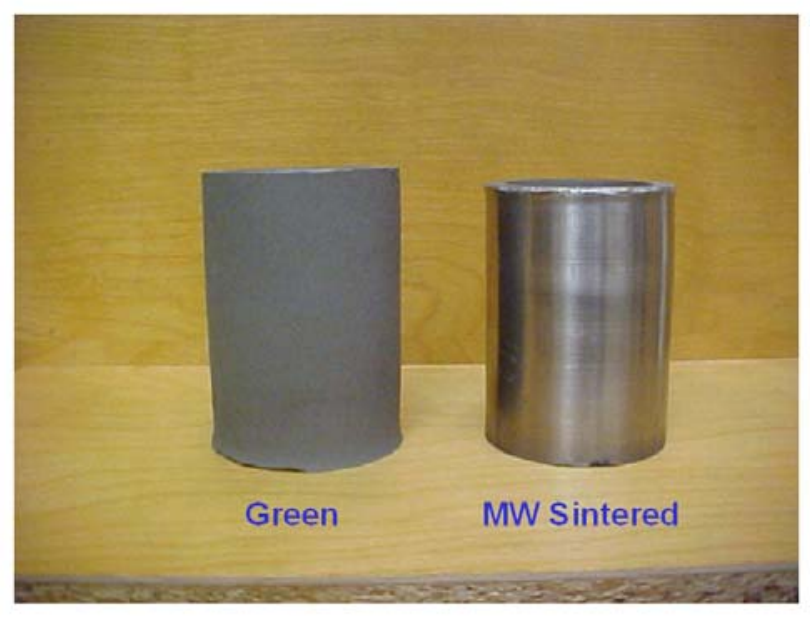

Figure 3.3. Green CIPed samples (left) and microwave sintered at 1250C/15 min (right) 


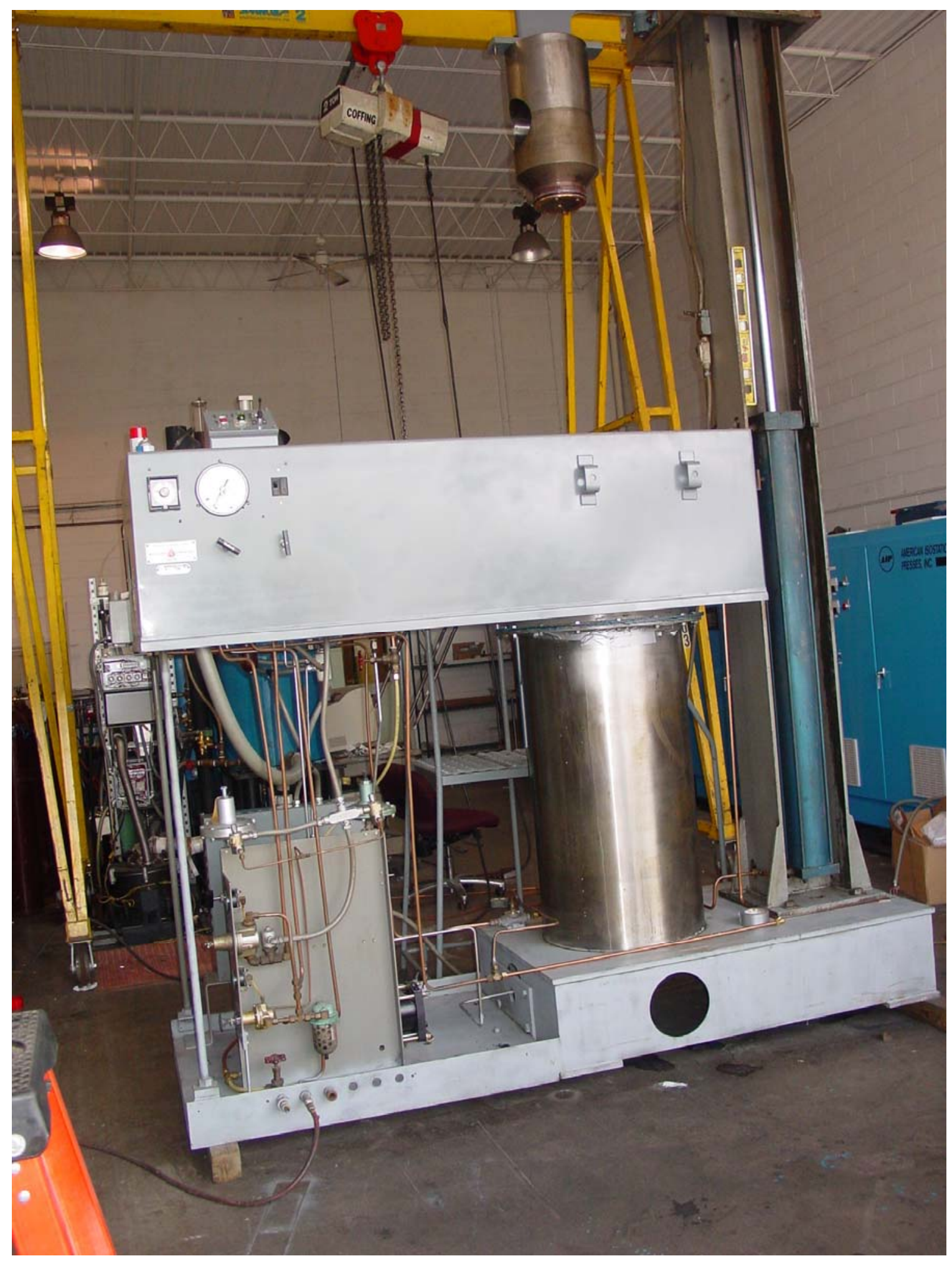

Figure 3.4: Cold Isostatic Press from American Isostaic Press to be used for making green tubes. 
4. Bonding of sintered rods using microwave heating: The first bonding tests were done with tubing but this configuration was found to be too difficult to work with in the beginning. To obtain representative bonding data in order to select the strongest bond, parts in rod shapes were either microwave sintered or commercially obtained for the tensile tests. Preliminary tests of foil vs powder for bonding have indicated that the foils do not couple very well to the microwave energy, as expected. Two approaches for bonding were adopted: (i) One-step method in which green parts with bonding powders were sintered and tested to obtain long coils. The approach was not successful since the bonding and sintering temperatures are different and when processed at a single temperature, it did not produce satisfactory bonding. (ii) Two-step process in which pre-sintered samples were joined using braze powder. For this a fixture was developed to assure alignment and apply force on the rods/bond during sintering. Four powder metals (50:50 Fe:Ni, 58:42 Fe:Ni, Co, Nitronic 30) were tested for identifying the right braze powder to produce highest bonding strength. After the initial manual lab strength tests by the operator, the mechanical testing was done on representative bonds using Instron machine and standard procedure. 50:50 Fe:Ni powder exhibited highest tensile strength of 54,313 psi which is quite a moderate value. This was obtained without any optimization of the processing conditions. The graphs of the stress data are shown in Figures 3.5-3.7. Further experiments were made 50:50 Fe:Ni powder to optimize the brazing conditions. After the surfaces were machined to a uniform diameter, the bonded rods with the 50:50 Fe:Ni powder had the highest tensile strength of 72,821 psi. This value is comparable with the conventional strength. We also prepared more samples using other brazes and commercial Nitronic 50 stainless steel. The tensile tests were made with the Nitronic 50 stainless steel rod but with typical metal/carbide high temperature/strength brazes. Using Dennis Tool Company braze technology, the rods were bonded with cobalt copper manganese and nickel copper manganese alloys. The results are shown in the table below:

Table 1: Tensile test results of the Brazed samples using various commercial powders

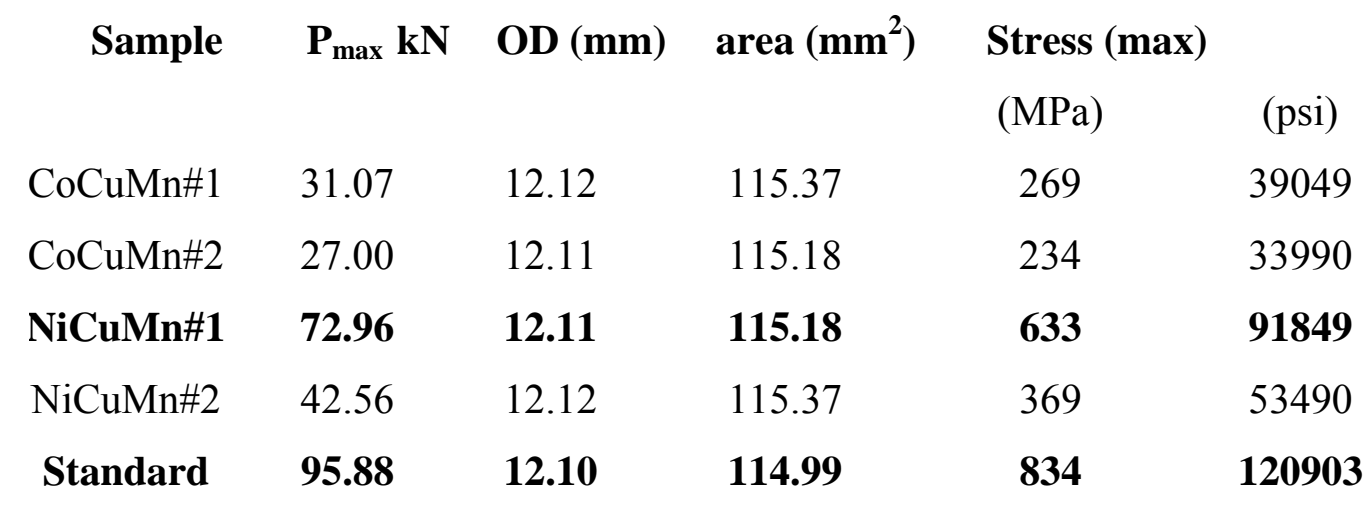


The standard is the tensile test of Nitronic 50 rod without any bond, which compares favorably with the literature result of $124 \mathrm{ksi}$ for annealed Nitronic 50 steel. This confirms that the testing procedure used here is accurate. The result of NiCuMn\#1 showed a tensile stress of about $92 \mathrm{ksi}$ which is excellent when compared with the standard value of the Quality Tubing's QT-16Cr80 (Coil-13941) composition.

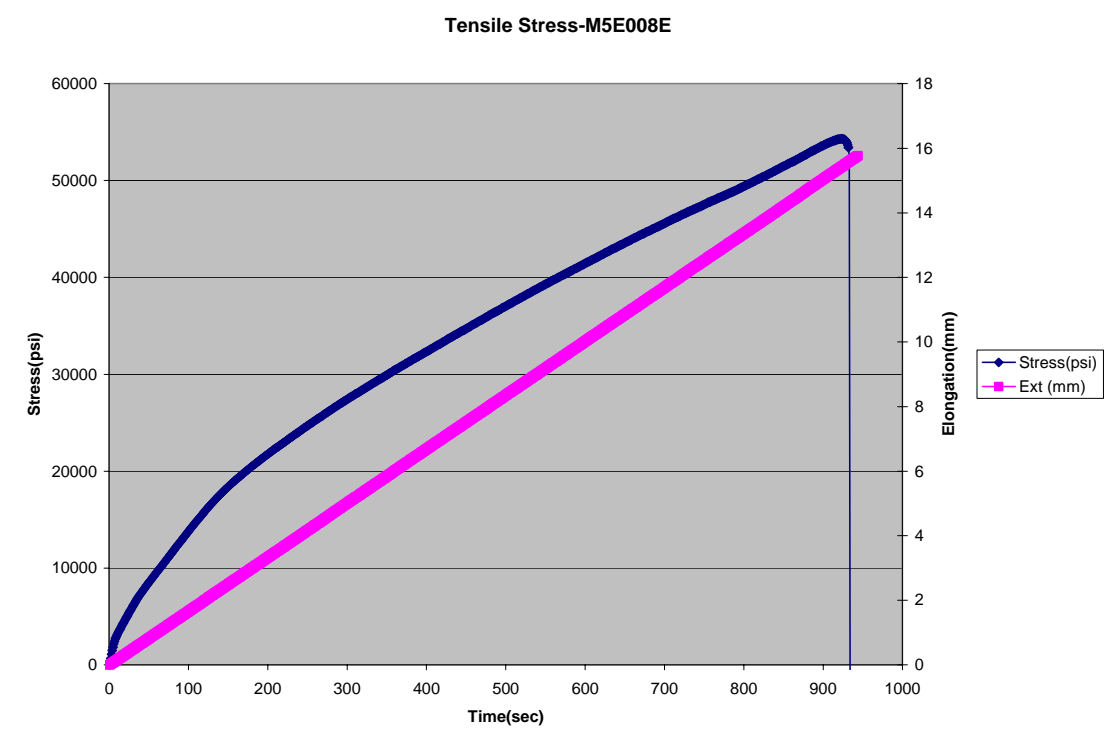

Figure 3.5. Tensile Stress data (stress and extension) of bonded sample using 50:50 Fe:Ni.

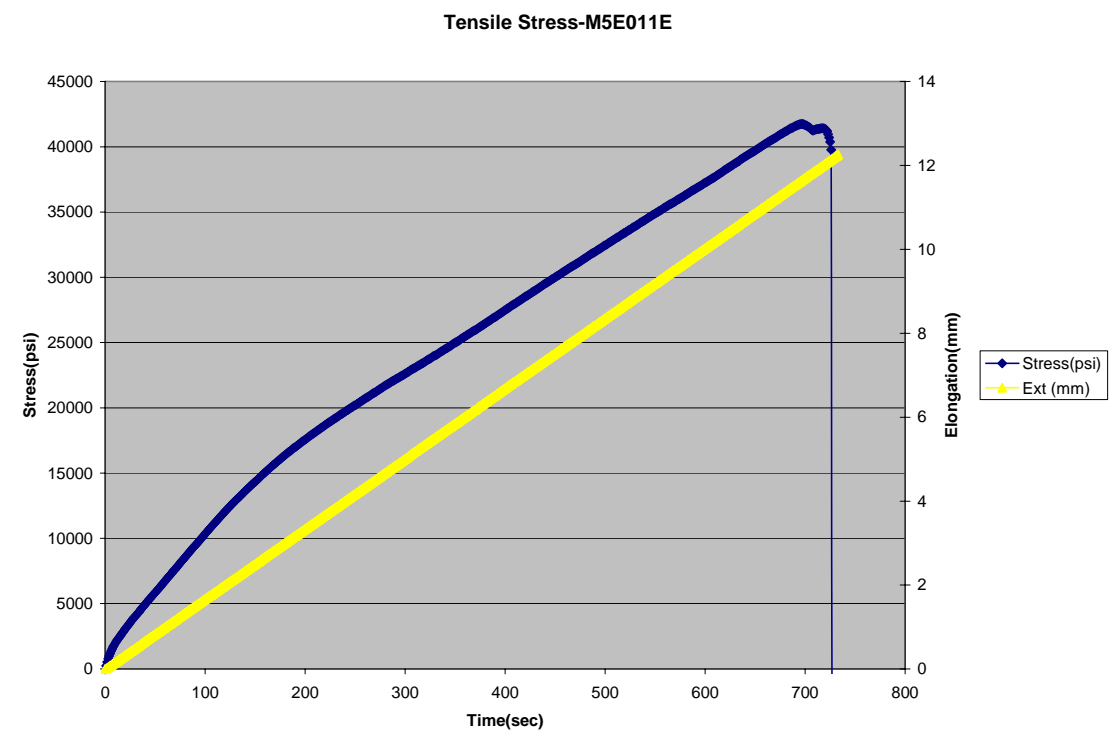

Figure 3.6. Tensile Stress data (stress and extension) of bonded sample using Co. 


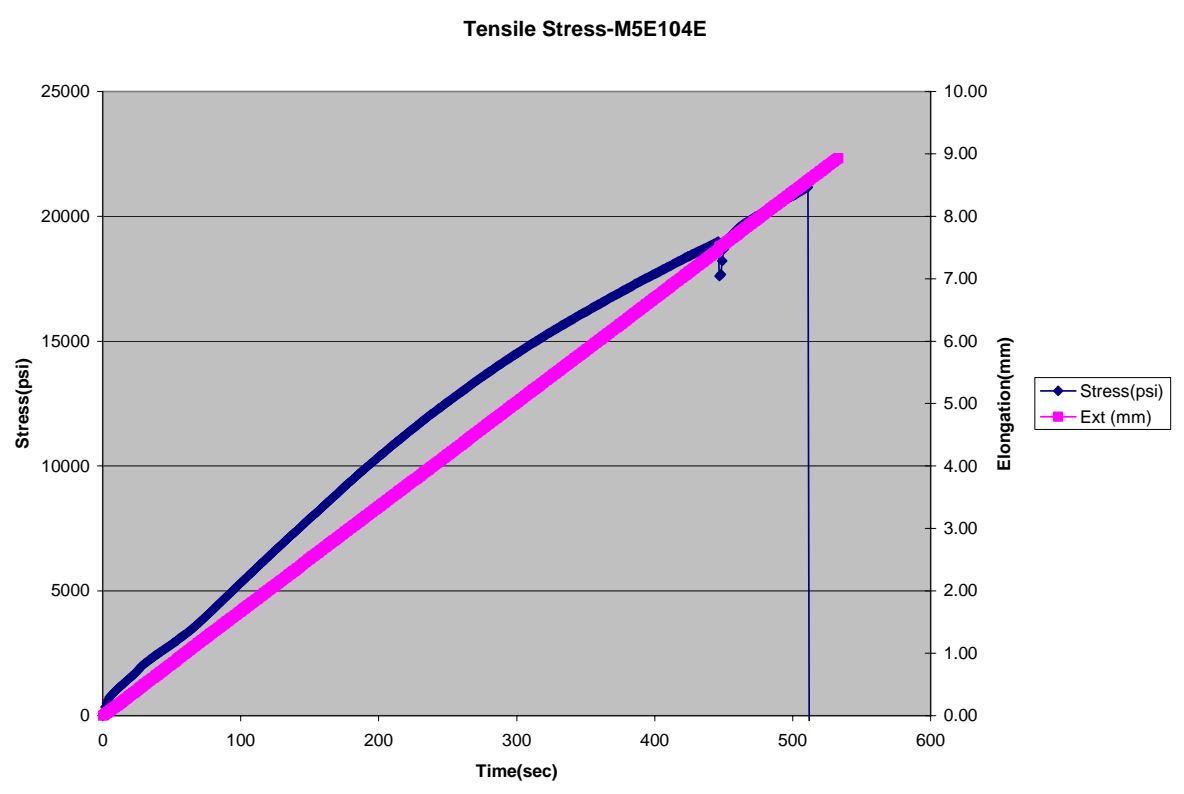

Figure 3.7. Tensile Stress data (stress and extension) of bonded sample using 58:42 Fe:Ni

\section{Mechanical properties tests:}

The experimental details of the mechanical tests performed at the Stress Engineering described below:

Several 12" long test samples were microwave sintered at Penn State University using the pre-alloyed 316L material and optimized sintering conditions in the regular vertical continuous 2.45 $\mathrm{GHz}$, multimode sintering system. This system was suitable modified to process such tubular samples. The green tubes of 12 inch in length and nominally 1.15" OD 1" ID were prepared using cold isostatic pressing (CIP). The binder burn out of these green samples was conducted in a conventional furnace separately. Before attempting 12 inch tubes, several smaller tubes (3-5 inch) were also fabricated for crush and corrosion tests. All sintered samples were sent to Dennis Tool Company (DTC) for machining and brazing to make long (up to 48 inch) tubes for fatigue tests. At DTC these samples were cut, machined, brazed, as needed and finally were packaged for testing at Stress Engineering Services. The experimental procedure for these tests is described below:

5.1 Torsion Test: Two brazed tubing assemblies (sintered stainless steel) were be loaded in torsion to failure. The tests were performed in a machine that includes an encoder to monitor the rotation and a torsion load cell to monitor the torque. Figure 3.8 shows a sample in the machines both with and without the safety shield. The machine is normally used to compare the friction characteristics of thread lubricants, but it is well suited for the torsion failure tests. Both samples were loaded to failure. The 
torque and rotation was recorded by a high speed data acquisition system. The yield and failure torques were used to calculate the yield and failure shear stresses based on the nominal pipe OD and ID. Since the torque machine is set up to use standard sockets, the shanks of $3 / 4$ " bolts were turned down to slid into the ends of the samples and welded to the tube, resulting in hex bolt head at each end of the samples, as shown in Figure 3.9.

5.2. Crush Test: Four 3" long samples were crushed. A 20,000 lb capacity Baldwin load frame was used to crush the tubing. The displacement and load required to crush the tubing radially (laying flat on its side) was recorded. The tubing was visually examined for cracking after being crushed.

5.3. Micro hardness Test: Two tubing samples containing brazed joints were supplied for micro-hardness evaluation of the brazed joints. A view of the two brazed joints (following sectioning) is presented in Figure 3.10. As can be seen, both tubing samples were sectioned along their longitudinal axes. Half of each brazed sample was subsequently mounted in plastic for examination of the structure and hardness of the brazed joint. The mounted portions of the tubing samples are shown toward the top of the field of view in Figure 10-A.

5.4. Corrosion Test: Corrosion tests were performed in an autoclave at $250^{\circ} \mathrm{F}$ and $500 \mathrm{psi}$ for 96 hours with carbon dioxide bubbled through a 5\% sodium chloride solution to provide $100 \%$ saturation of the brine. Test procedures from ASTM G31 and G111 were used as a guide.

5.5. Fatigue Test: Stress Engineering Service's resonant fatigue test machine was used for the fatigue tests. The resonant fatigue machine consists of two supports, a variable speed electric motor, drive housing, and dead end housing. Figure 3.11 shows the sample in the fatigue machine. The variable speed motor rotates an eccentric mass in the drive housing clamped to one end of the sample and loads the pipe. The rpm of the motor is adjusted to load the sample near its natural frequency. The applied load produces the same a sinusoidal alternating stress at every point around the circumference of the sample. The dead weight housing is clamped to the other end of the sample to balance the assembly. The test sample length required and the resulting test frequency were determined using a finite element model. Axial strain gages on the outer diameter of the center section of the tube were used to monitor the bending strains during the fatigue test. Both bending strains and number of cycles were monitored and recorded by the fatigue data acquisition system. Each minute the data acquisition software recorded the average maximum and minimum strains for each strain gage along with the number of cycles. 
Two mechanisms are normally used to stop the test if the sample has cracked through the wall during fatigue testing: wet detectors and pressure switches. However, the test was performed without water in the sample the test stopped when the crack was large enough to reduce the stiffness of the sample enough to lower the natural frequency of the sample so that the stress range will drop.

Test Procedure: The general steps, involved in testing the sample, were:

1. Measure and record the wall and outer diameter at each strain gage location.

2. Install the strain gages to monitor the fatigue strains.

3. Load the sample in the fatigue test machine.

4. Adjust the rpm of the test machine to achieve the desired strain range.

5. Log strain amplitude, frequency, and cycles.

6. Fatigue test the sample until failure.

7. Inspect the sample.

8. Document the test including fatigue test strains and cycles.

6. Fabrication of Test Samples: In order to get a sample long enough to test in the resonant test machine five short (about 9" long) sections of tube were joined with stainless steel sleeves and brazed together, as shown in Figure 3.12. The center of the middle section was turned down so the failure would occur in the middle of the sample. A total of eight axial strain gages were installed to monitor the test, four at $90^{\circ}$ intervals around the circumference on either side of center of the turned section in the center of the sample. The sets of four gages were offset by $45^{\circ}$ so that there was a gage every $45^{\circ}$ around the circumference of the sample as shown in Figure 12. The ID and OD at the strain gages were not concentric. The OD at the gages was 0.799 " and the ID was 0.595 ". After the sample broke, the diameters were measured along with the wall thickness at each strain gage. The thicknesses at the gages are given below.

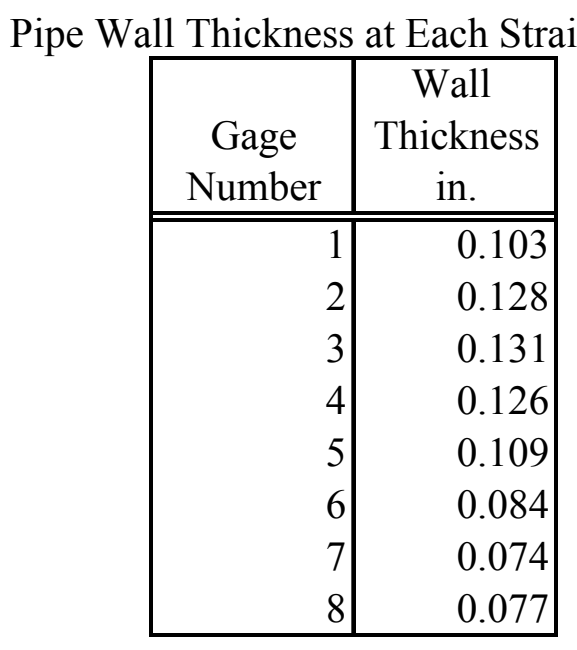




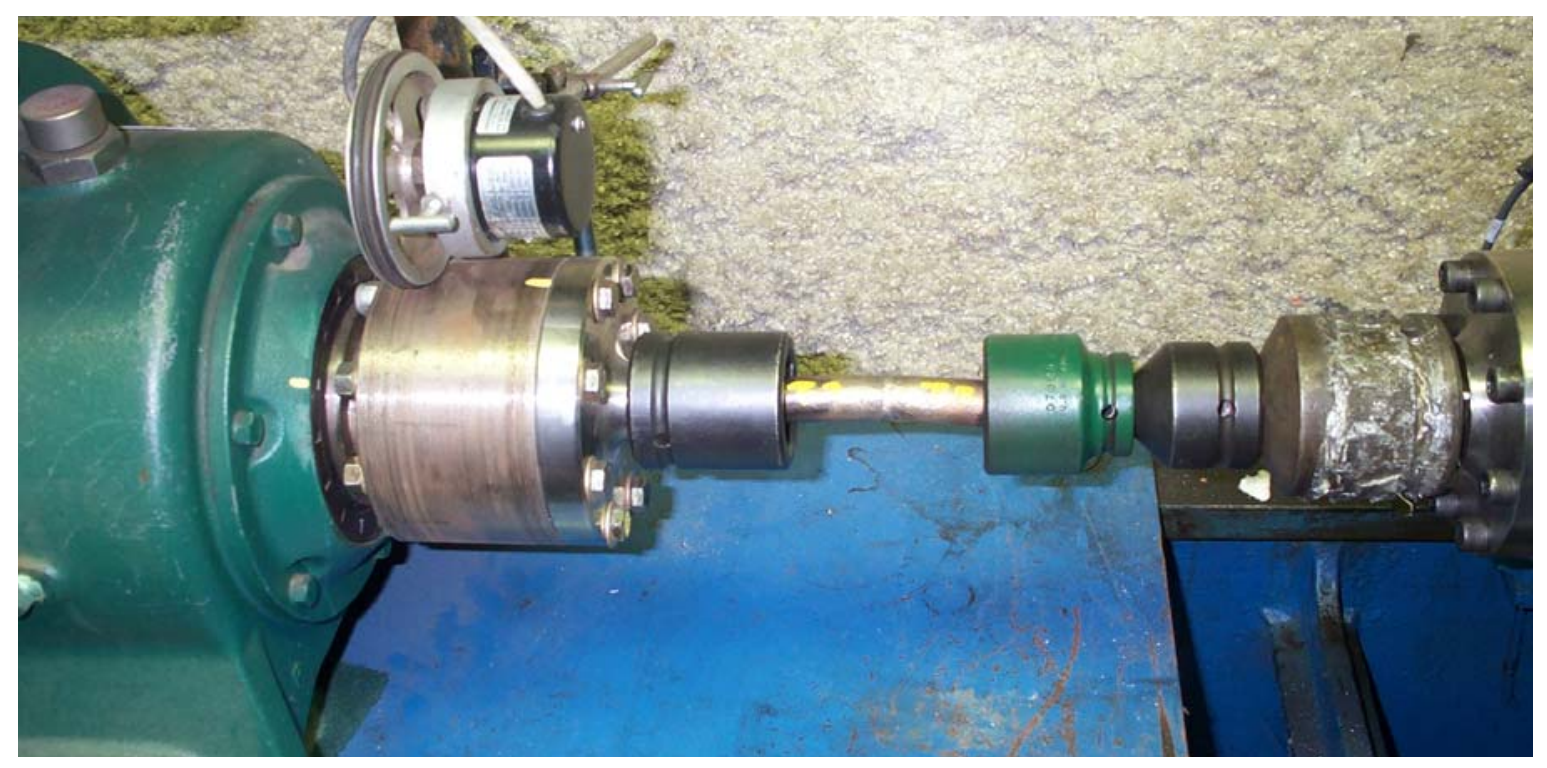

A. Sample In Torque Machine (without safety shield)

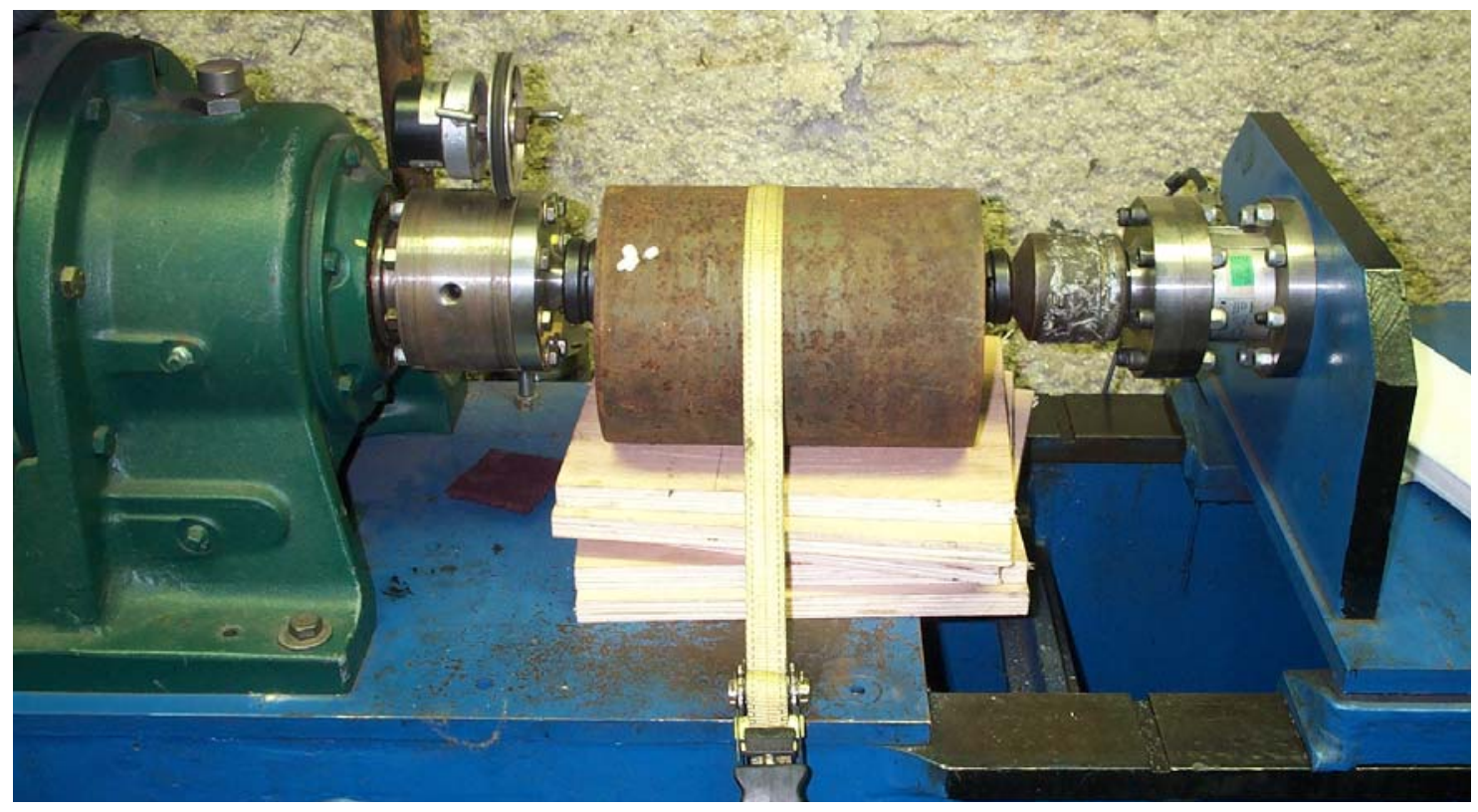

B. Sample In Torque Machine (with safety shield)

Figure 3.8: Torque test performed on the sample: Samples in torque machine: A. without safety shield, and B. with safety shield. 


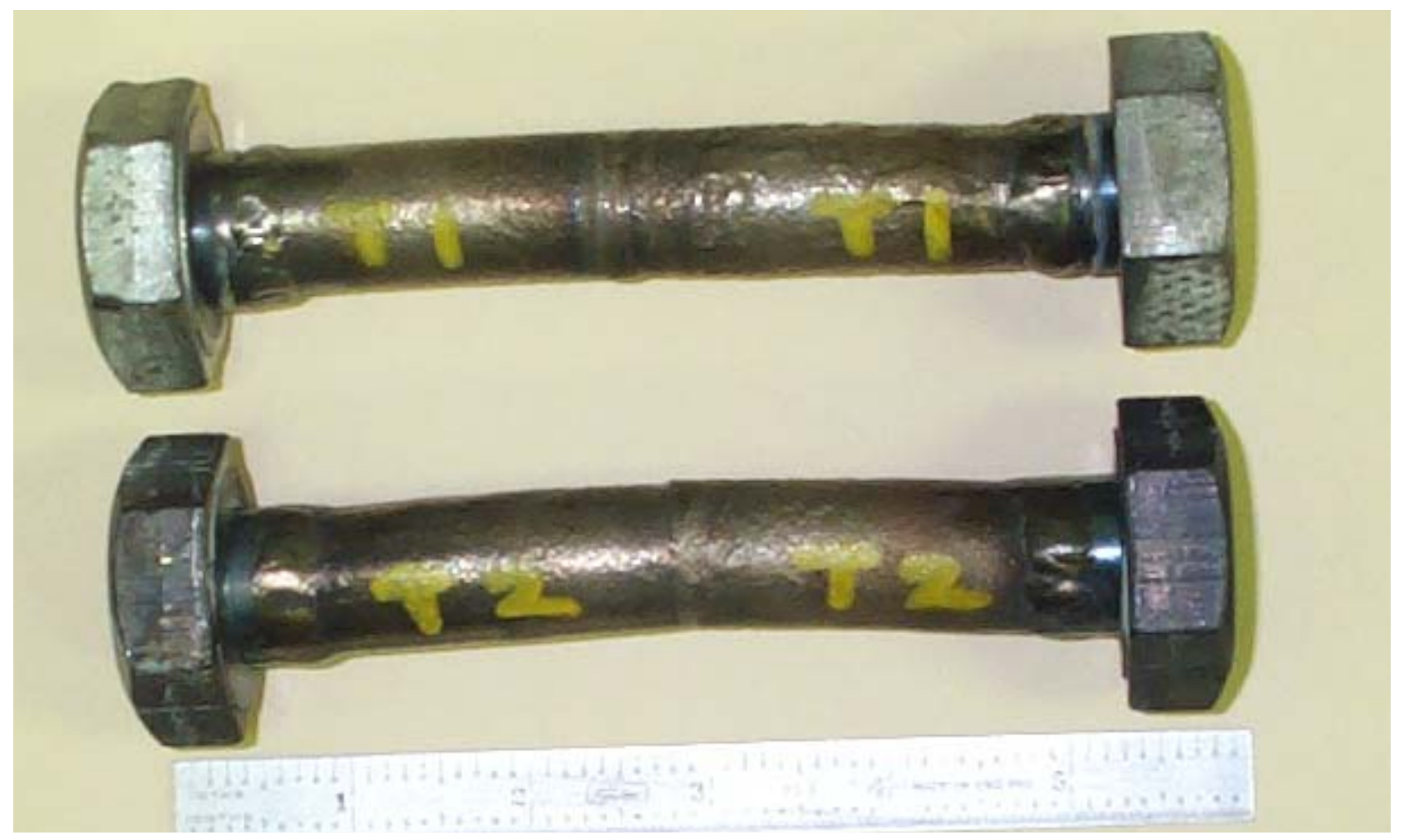

Figure 3.9: Torsion test samples before test. 


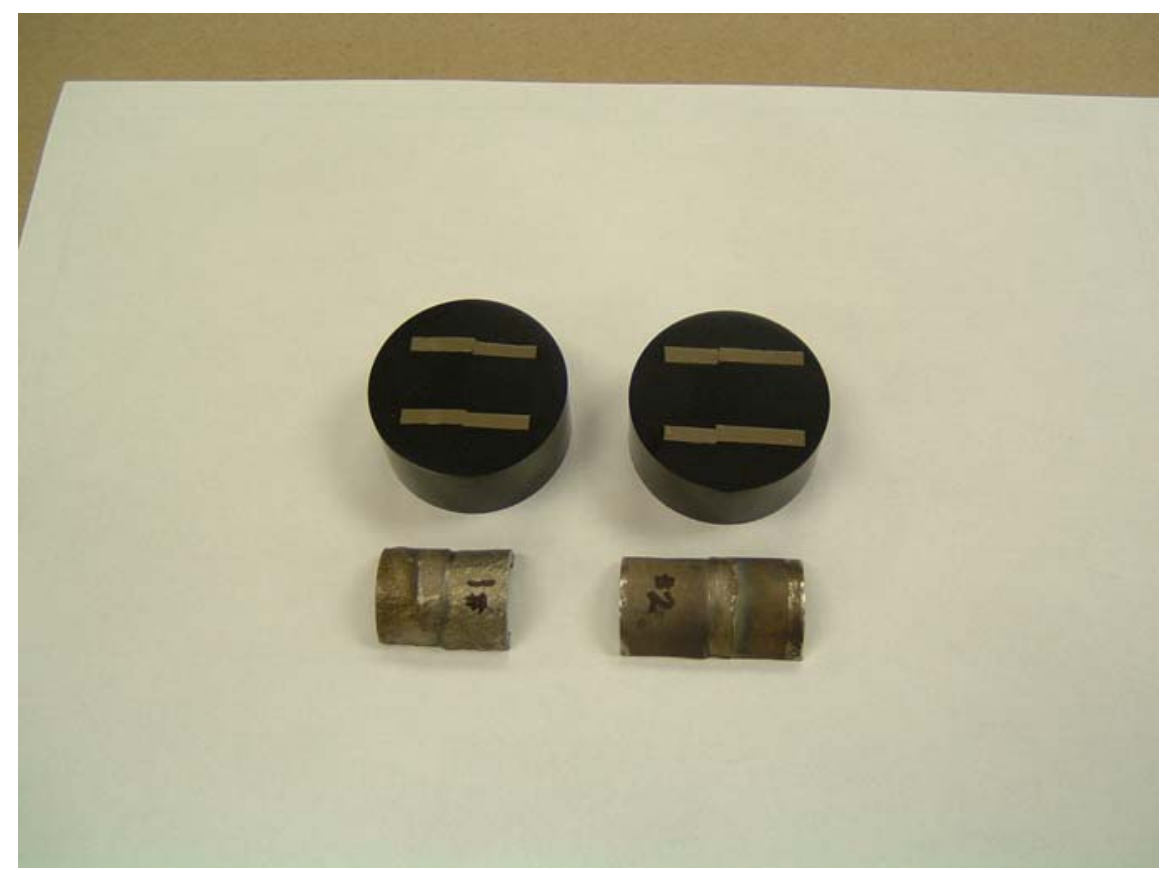

A. A view of the samples containing the brazed joints (taken following sectioning and mounting).

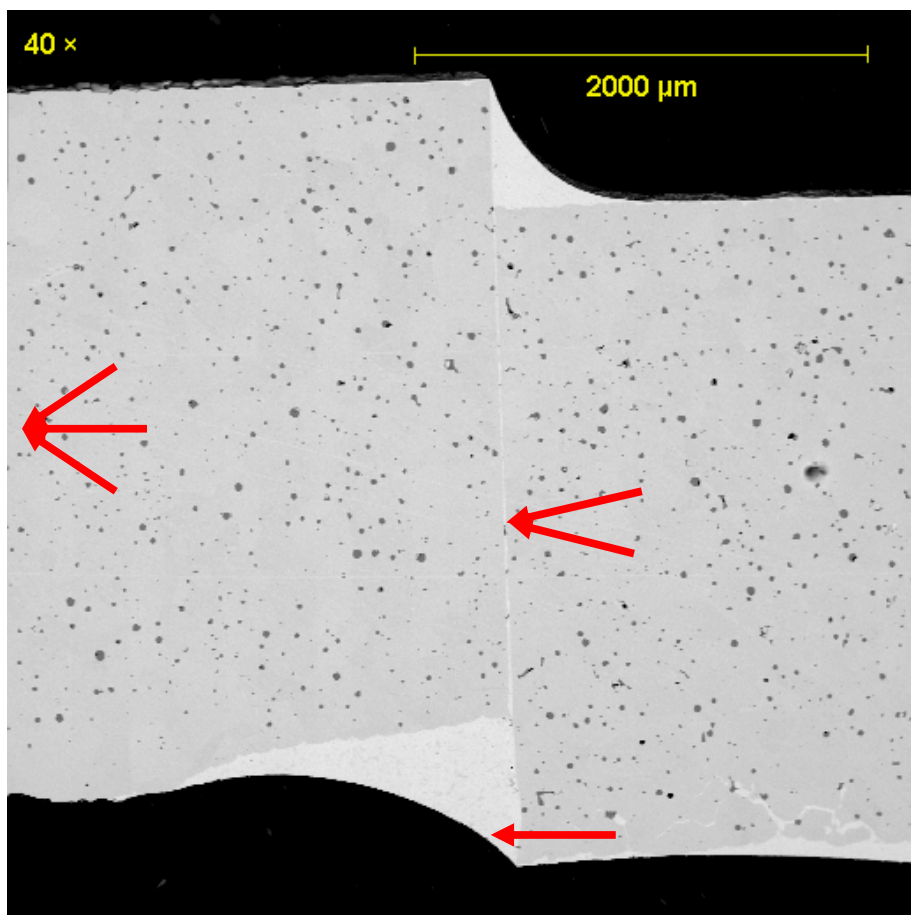

B. A back-scattered electron image of a cross-section through the joint in sample 1. Locations where hardness measurements were made are identified.

Figure 3.10: Microhardness photographs 


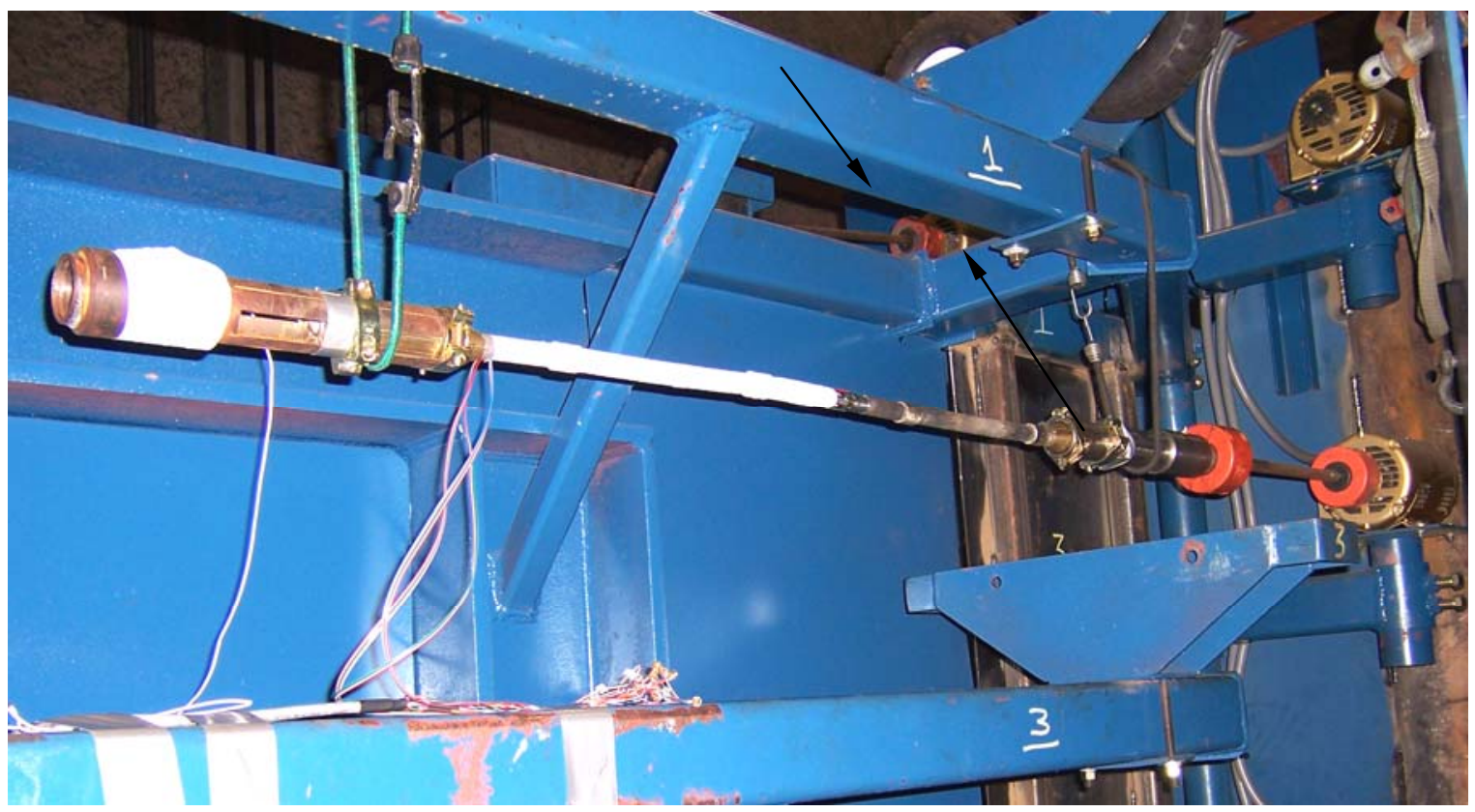

Figure 3.11: Sample in fatigue test machine.

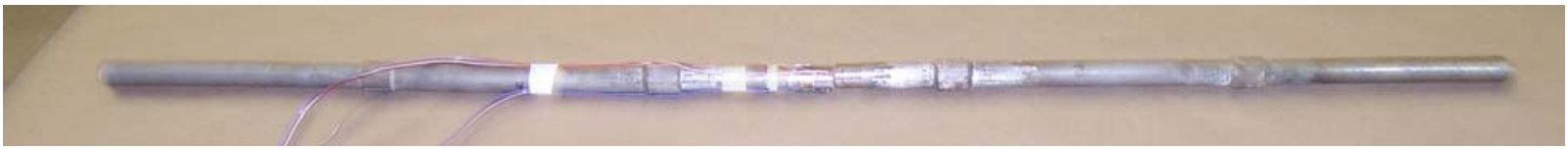

\section{Overall Sample}

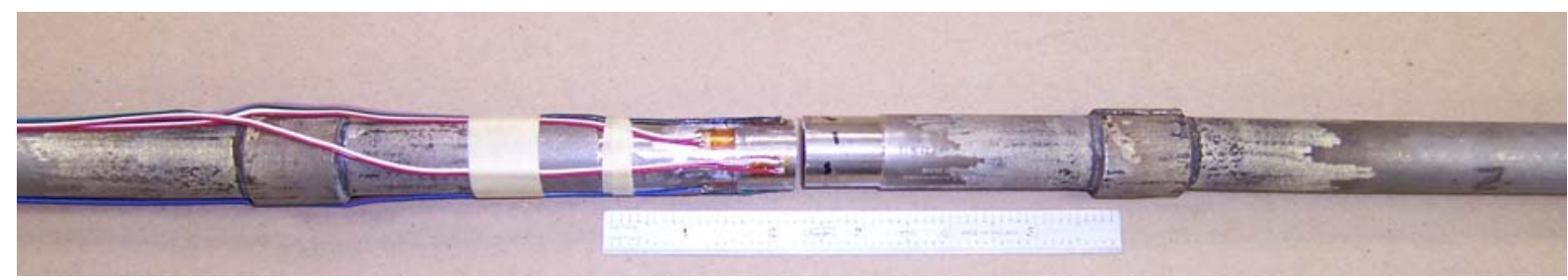

Center Section with Typical Brazed Sleeves Connecting Sections of Sample

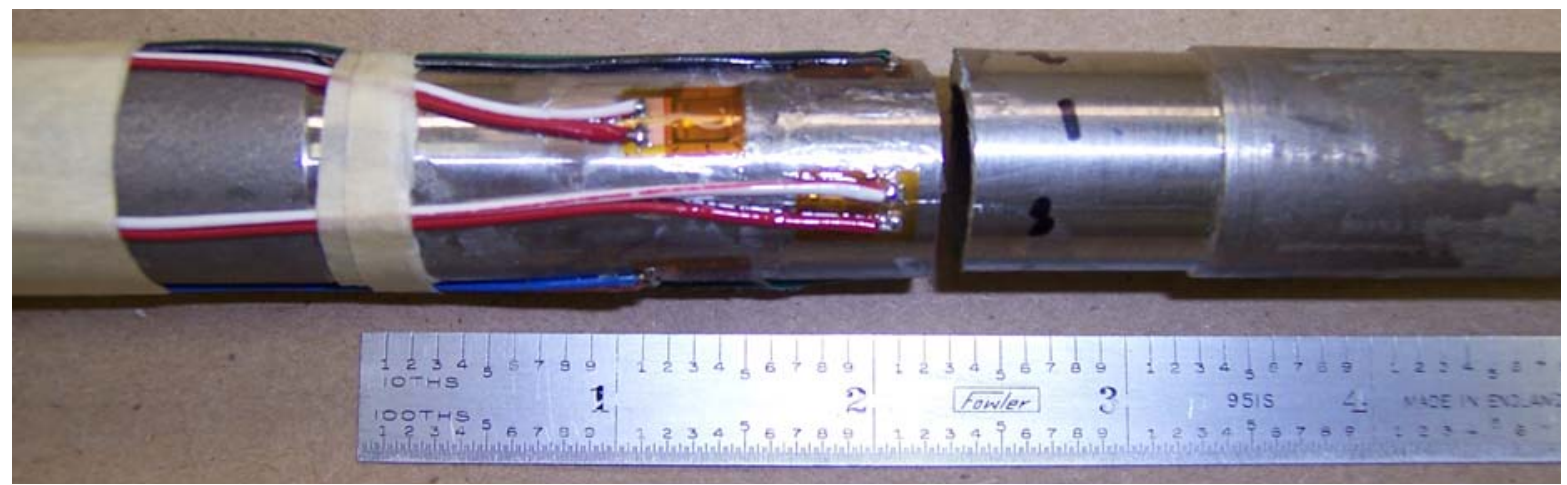

Strain Gages in Center of Turned Section

Figure 3.12: Sample in the fatigue machine after testing at different magnifications. 


\section{Results and Discussion}

In this final report only the results of the mechanical properties are provided:

\section{Torsion Test:}

Figures 4.1, 4.2 and 4.3 show the samples after the tests. Black axial lines were drawn the samples prior to the tests. Figure 4.1 shows that the lines on sample T1 are helical while the lines on sample T2 are almost straight. Sample T1 failed 0.15 " from the braze joint while the failure in sample $\mathrm{T} 2$ was 0.25 " from the braze joint. The torque rotation plots, for the two samples, are shown in Figure 4.4. Sample T1 twisted 132.4 degrees prior to failure while sample $\mathrm{T} 2$ only twisted 24.6 degrees. Both samples started to yield at $220 \mathrm{ft}-1 \mathrm{~b}$. The failure torques were $393.8 \mathrm{ft}-\mathrm{lb}$ for sample T1 and $273.3 \mathrm{ft}-\mathrm{lb}$ for sample T2.

Shear stresses at the yield and failure torques are calculated based on the tests of samples T1 and T2 using tube dimensions of 0.79 " OD and 0.56 " ID. The shear stresses at yield and failure were:

At yield: Samples T1 and T2

Torque at start of yield $=220 \mathrm{ft}-1 \mathrm{~b}$

Shear Stress $=\tau=36,480 \mathrm{psi}$

At failure: Sample T1

Torque at failure $=393.8 \mathrm{ft}-\mathrm{lb}$

Shear Stress $=\tau=65,300 \mathrm{psi}$

Sample T2

Torque at failure $=273.3 \mathrm{ft}-\mathrm{lb}$

Shear Stress $=\tau=45,320 \mathrm{psi}$

Isolating the braze joint in two samples for torsion $(45,320-65,380 \mathrm{psi})$ was intended to provide feedback concerning a proposed joining method for future microwave tubing samples to be fabricated in this manner. The results indicate that the shear failure stress of the microwave sintered material and the corresponding braze joint in one case is above nominal and in one case below nominal for 316L type stainless steel (annealed). The typical tensile stress shown for 316L stainless is 78,000 psi (annealed) and the corresponding shear stress (@.75 x 78,000) is 58,500 psi. The Quality Tubing materials for coiled tubes is QT16Cr for example, (taken from QT report - 2004') shows an average tensile strength of 122,470 psi. 


\section{Crush Test:}

Prior to the test the samples were numbered C1, C2, C3 and C4, as shown in Figure 4.5. Figure 4.6 shows a sample in the load frame. Figure 4.7 shows the load displacement plots for the four samples. The load frame has low and high low ranges and the initial tests were performed by loading the samples to the maximum of the low load range. Samples C2, C3, And C4 cracked during loading at the low load range. Sample C1 did not crack at the low load range and it was subsequently loaded until it was flat. Sample C1 did not crack.

The supplied microwave samples for the crush tests were not the best we have seen (23.661.1 kips). In crush tests performed several times at Dennis Tool Company, it was noted that the sintered density of the sample plays a critical role in its resistance to cracking during the test. With good density, we have seen consistent results that are similar to the "C1" crush test sample above. These results compare very well against previous microwave samples tested in the QT report from 2004, and performed quite satisfactorily. Some crushed samples became totally flat without showing any cracks as shown in Figures 4.8 and 4.9.

\section{Micro hardness Test:}

Following polishing and etching, micro-hardness measurements were made on the brazed joints in the mounted samples. The original Vickers micro-hardness measurements were converted to equivalent Rockwell B values. For both samples, hardness reading \# 1 was taken in the braze alloy, near the surface of the sample, outside of the thin braze zone. Reading \# 2, on the other hand, was taken near mid wall in the center of the thin braze alloy layer. Reading \# 3 for each sample was taken in the wall of the tube, remote from the braze zone. The approximate locations of the hardness measurements are shown by the arrows Figure 3.3 B and Figure 4.10 A.

The hardness of the braze alloy ranged from approximately Rockwell B 70 to Rockwell B 79. The hardness of the tube wall, on the other hand, was somewhat higher, in the range of Rockwell B 81 to Rockwell B 92.

The structures of the braze joints can be seen in Figure 3.3 B and Figure 4.10A. The lighter areas in these photographs thus represent regions of higher average atomic weight and the dark areas are from regions of relatively low average atomic weight. The braze alloy can thus be seen to have a somewhat higher average atomic weight that the wall of the adjacent tubes. The tubes, on the other hand, can be seen to contain a relatively high concentration of low average atomic weight particles or 
precipitates. A high magnification view (originally taken at $500 \mathrm{X}$ ) of the braze joint in sample \# 1 is shown in 4.10B, from which we estimated the maximum thickness of the braze alloy in the joint to be approximately 0.0004 inches $(0.4$ mils). The compositions of the braze alloys and the tube walls were subsequently evaluated using the "energy dispersive x-ray spectrometer", (EDS), attachment of the SEM. An SEM-EDS scan gives a semi-quantitative estimate of the chemical elements that are in the small area of the sample surface that is excited to emit x-rays by the focused electron beam of the SEM. This study shows the compositions of the tube base metals, and it was found that the metallic part of the tubes consisted primarily of iron, chromium, nickel, manganese and molybdenum. A review of alloy literature showed that the tube wall apparently came closer to satisfying the chemical requirements for Nitronic 60 than those for Type 316 S.S., as initially suspected. The braze metal, on the other hand, was found to consist primarily of copper, manganese, nickel and iron. The tube walls also contained a relatively high concentration of low average atomic weight particles. These particles were found to consist primarily of oxygen, silicon and manganese.

\section{Corrosion Test:}

Two samples of tubing were sent to an outside test facility (Honeywell International, Houston, Texas) for corrosion testing. The two samples (after their return from the corrosion testing) are shown in Figure 4.11. The samples were exposed for a period of 96 hours to $5 \% \mathrm{NaCl}$ brine at room temperature, under $500 \mathrm{psi}$ carbon dioxide. The measured corrosion rates for the two samples were found to be $4 \mathrm{mils} / \mathrm{yr}$ and $14 \mathrm{mil} / \mathrm{yr}$. This compares with QT-16Cr rates of 2-3 mils/yr., QT-900 rates of 19-21 mils/yr., and 13\% Cr rates of 20-28 mils/yr. (data via Quality Tubing website).

The corrosion data suggests that the microwave sintered performed better than QT-900 and $13 \% \mathrm{Cr}$ tubing material, but not as good as QT-16Cr. Throughout our experiences in sintering with the microwave system, we have consistently seen noticeable, and sometimes, dramatic improvement in corrosion resistance. The samples supplied to Stress Engineering were not surface prepped in any way (these samples were EDM cut at each end) and perhaps would have given much better results if ground finish on all surfaces before testing.

\section{Fatigue Test:}

The test was performed at three different stress ranges. The first two stress ranges were due to changes in the response of the sample during the test and the third was an intentional increase in the stress range to shorten the test. The three stress ranges were combined into one equivalent stress range using Miners rule and a stress range to cycle relationship with $\mathrm{m}=-4$. Table 4.1 gives the strain gage 
results for the three stress ranges and the associated cycle counts. The equivalent stress range and cycle count are given in Table 4.2. Figure 4.13 compares the sintered tube test results to the BS $7608 \mathrm{~B}$ curve from British Standard "Fatigue design and assessment of steel structures, 1993". The results are also compared to the mean results for 57mm OD Super Duplex X670 umbilical tubes. The Super Duplex results were taken from "Effect of Reeling on Welded Umbilical Tubing Fatigue" OMAE 2006-92579.

The fatigue failure surfaces are shown in Figures 3.5 and 4.12. The sample failed near the center of the turned down section in the middle of the sample.

The test data seems to indicate that in some respects, the microwave sintered tubing performed as well as the comparable super duplex stainless steel tubing. Most notably is the fatigue test in which the failure of the microwave sample fell directly in line with the duplex failure slope. The microwave fatigue sample was made up of 5 separate pieces of tubing which were brazed together with a high strength, high temperature braze alloy. To ensure the test would focus on the sintered material and not a braze joint (which has been isolated and tested for strength), each braze joint was reinforced with a small, machined outer sleeve (Figure 3.5). The center section (mid-point along the length of the tubing assembly) O.D. was machined down to produce a clean surface on the O.D. Here, strain gauges were mounted allowing accurate measurements throughout the test. The wall thickness in this area of load concentration was somewhat variable due to the machining and less than perfect concentricity of the sintered O.D. to I.D.

The commonly used fatigue test in the coil tubing industry is a low cycle, high deformation test using a pressurized section of tubing (minimum sample of 72 " in length). Due to processing constraints, a homogeneous, uniform 72" microwave sintered sample could not be provided without braze or weld joints along the sample. In order to isolate the microwave material characteristics and eliminate a joining method testing variable, a high cycle, low deformation test was used at Stress Eng. This constrained the testing to a uniform, homogenous area along the microwave tubing sample. 


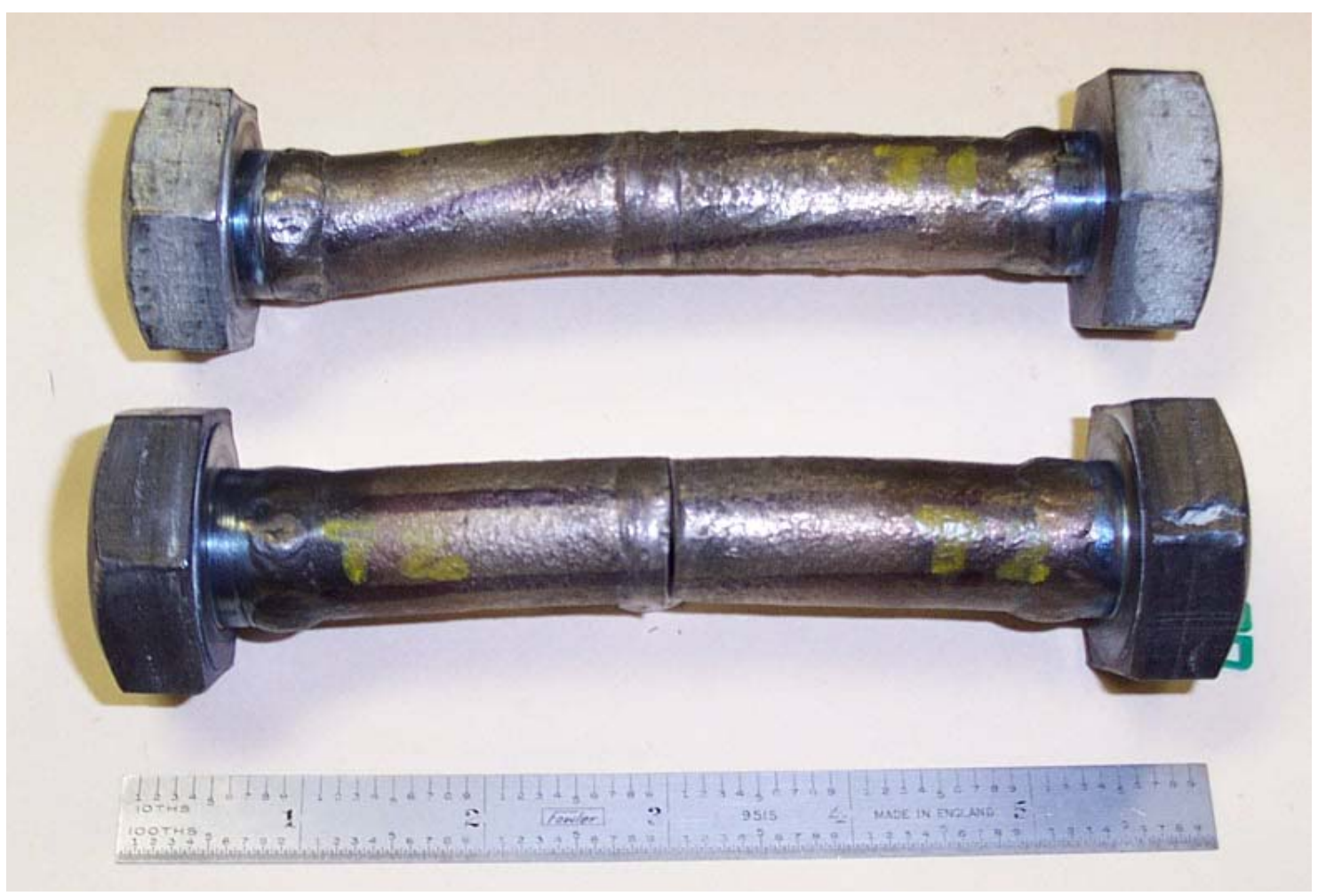

Figure 4.1: Torsion test sample after test (T1 top, $\mathrm{T} 2$ bottom)

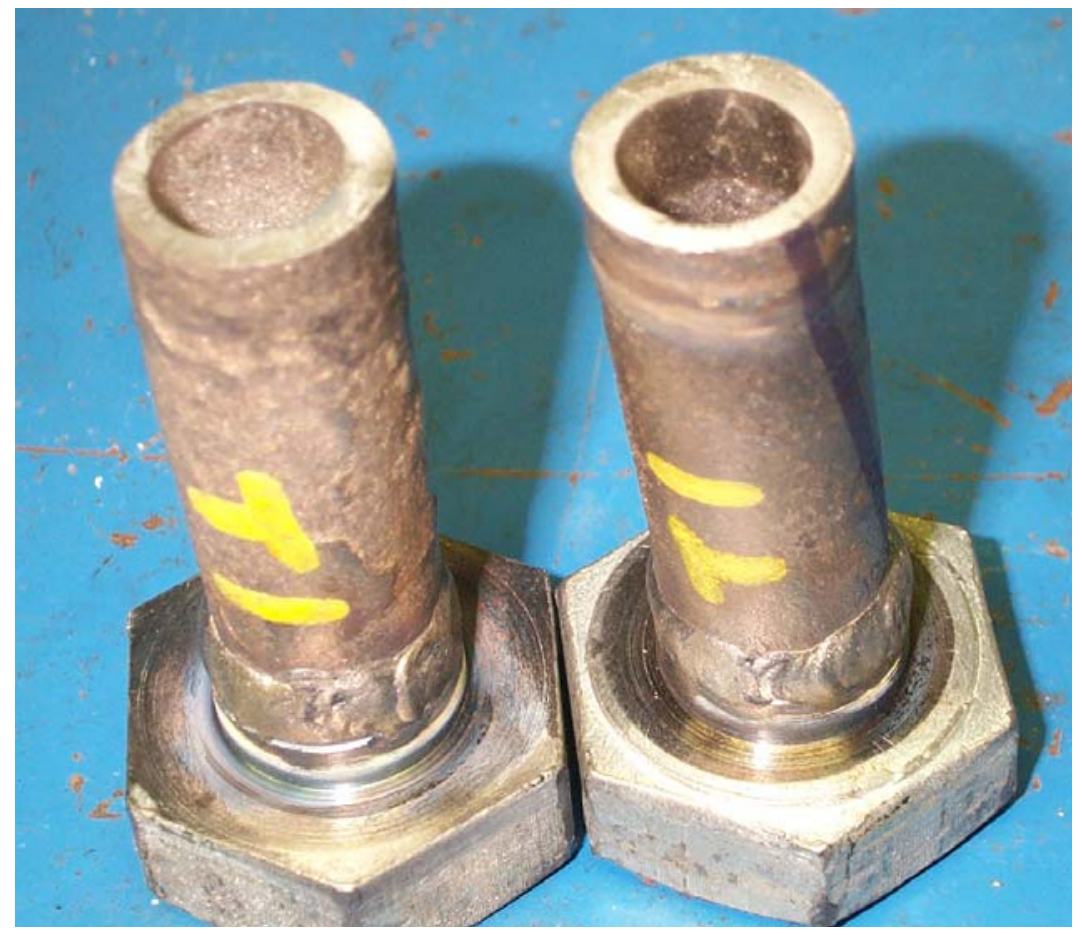

Figure 4.2: Sample T1 after test. 


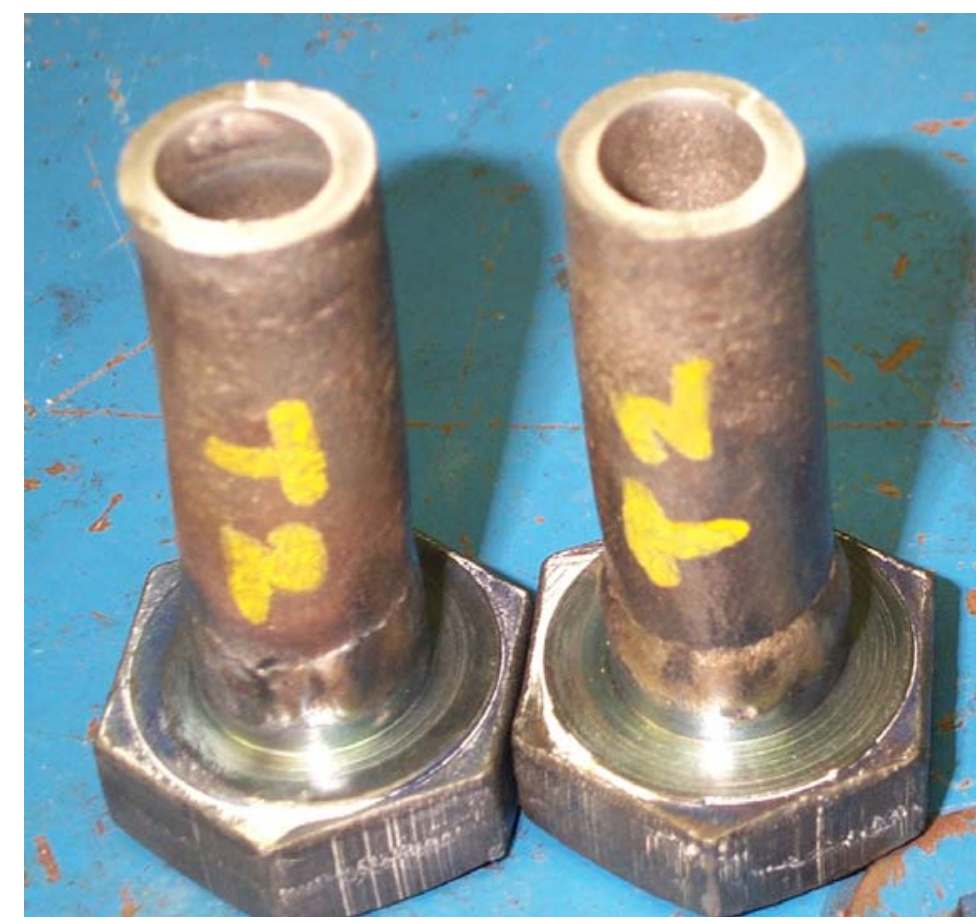

Figure 4.3: Sample T2 after test

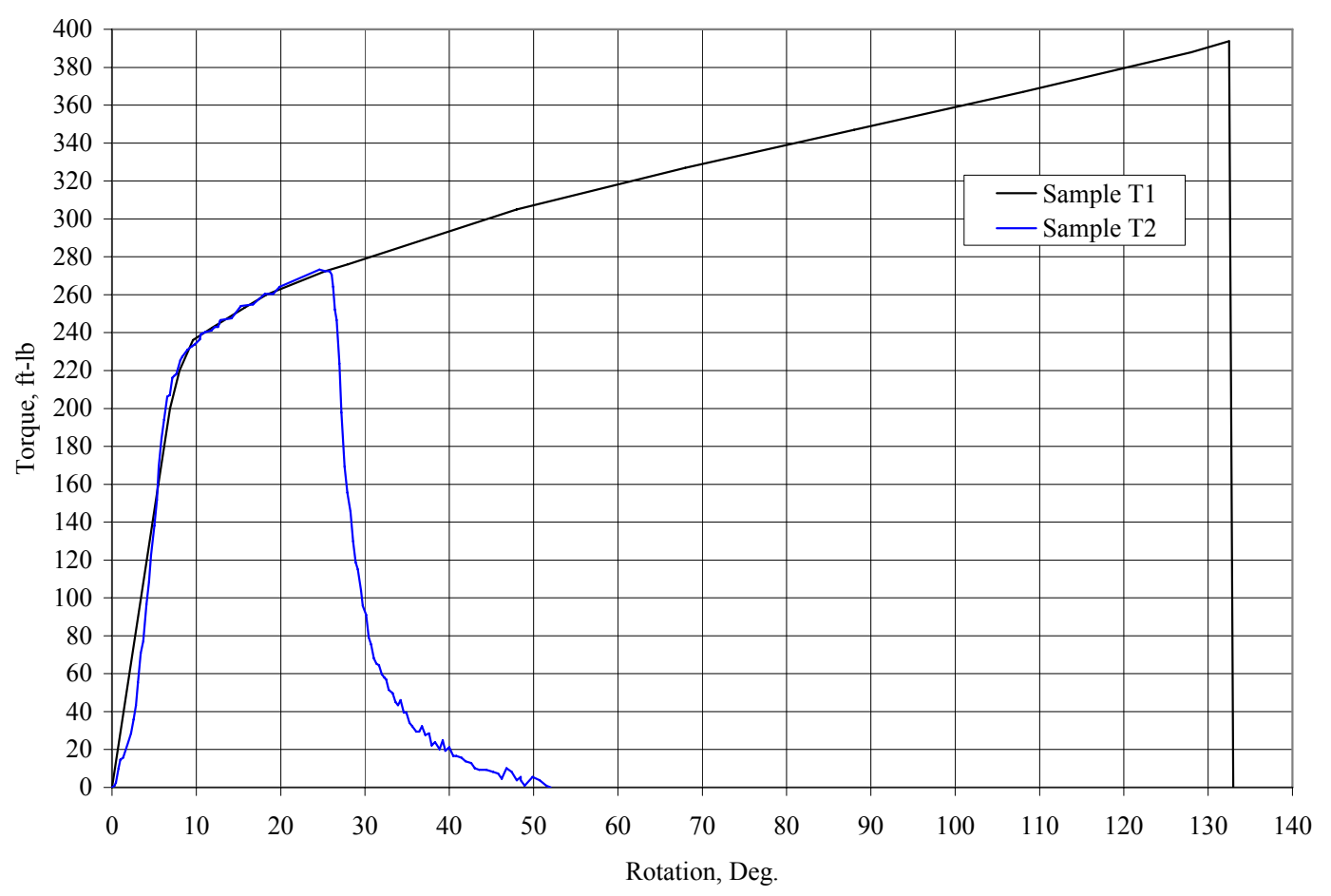

Figure 4.4: Failure torque test results. 


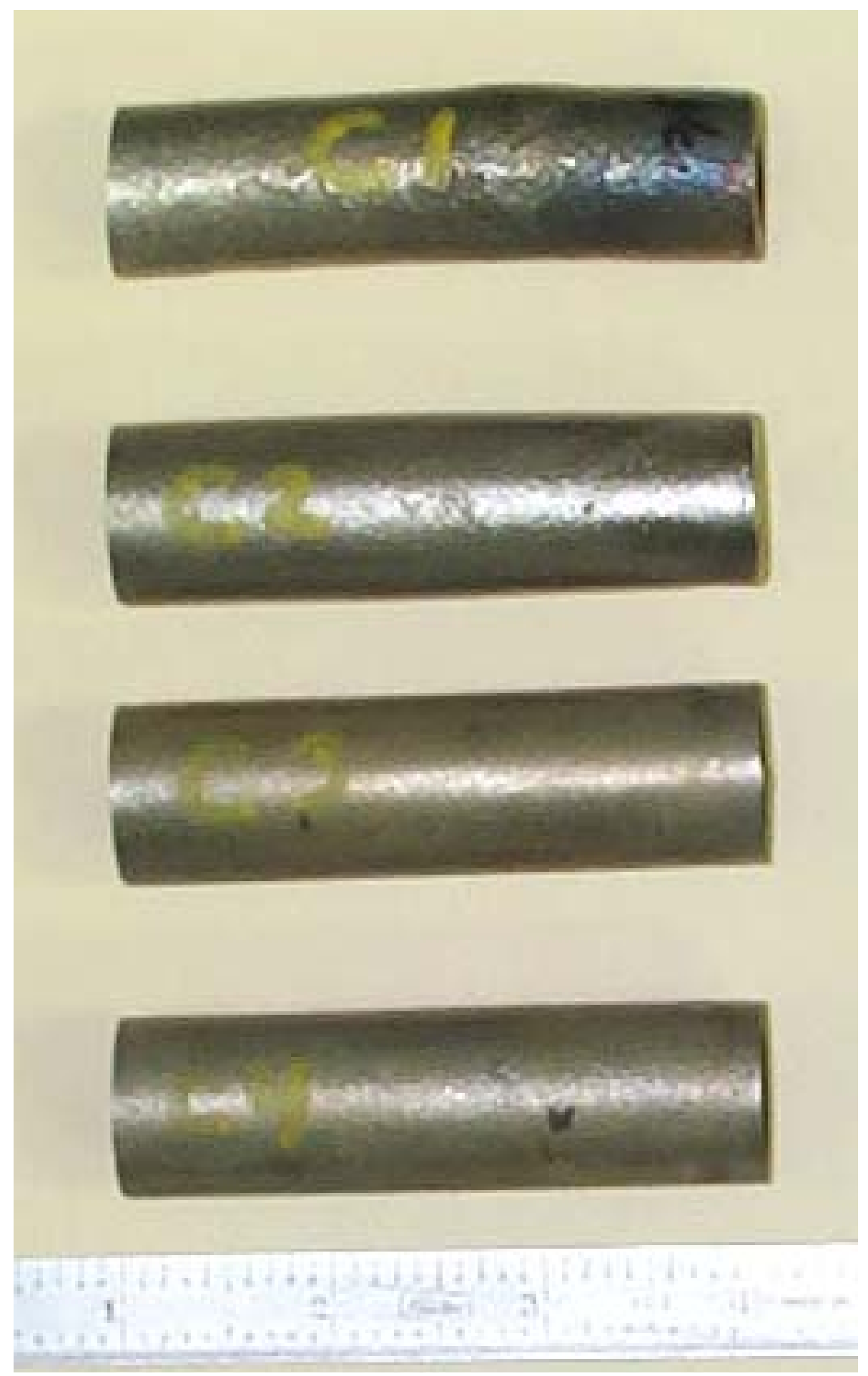

Figure 4.5: Compression test samples. 


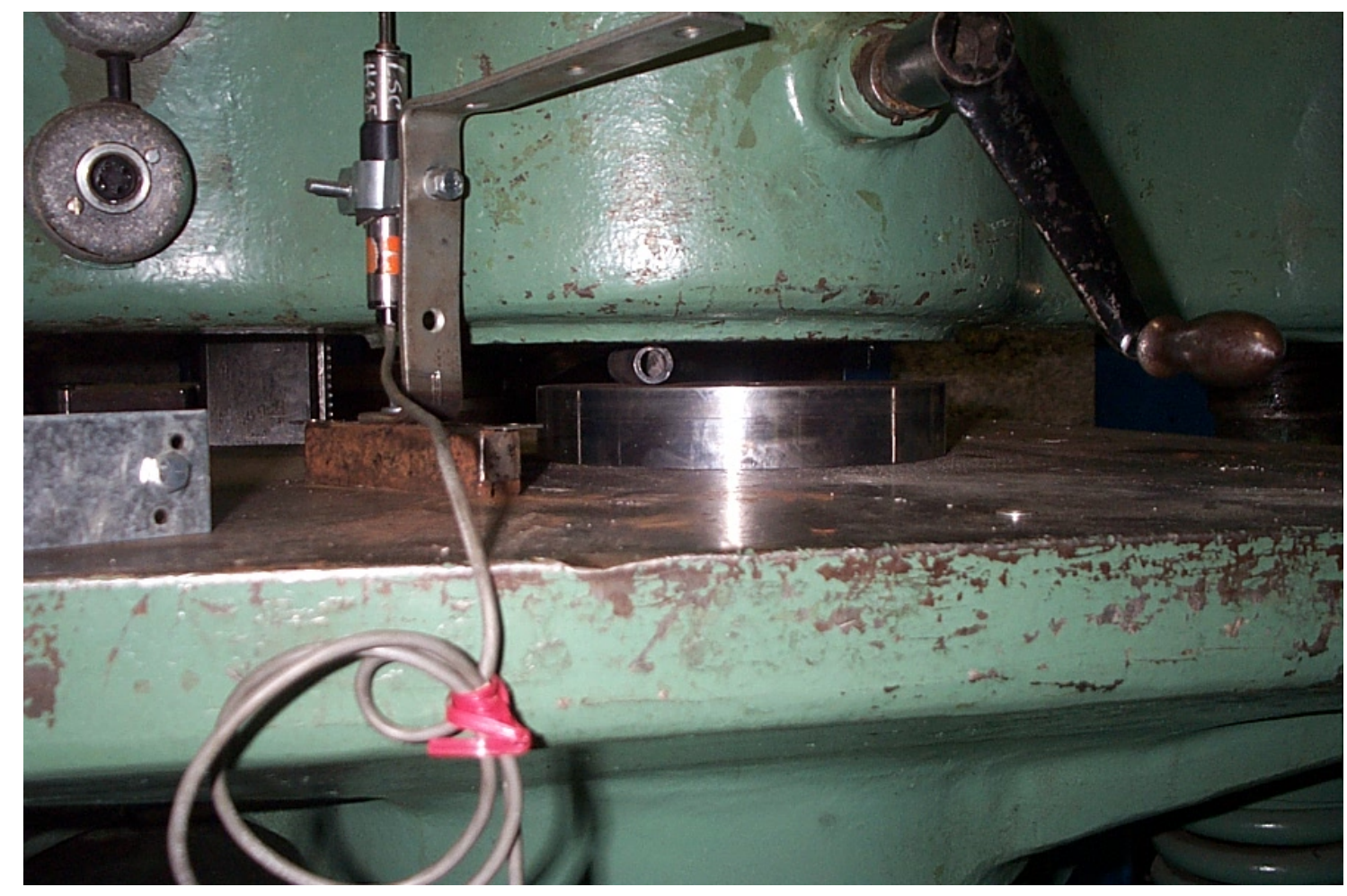

Figure 4.6: Compression sample in load frame.

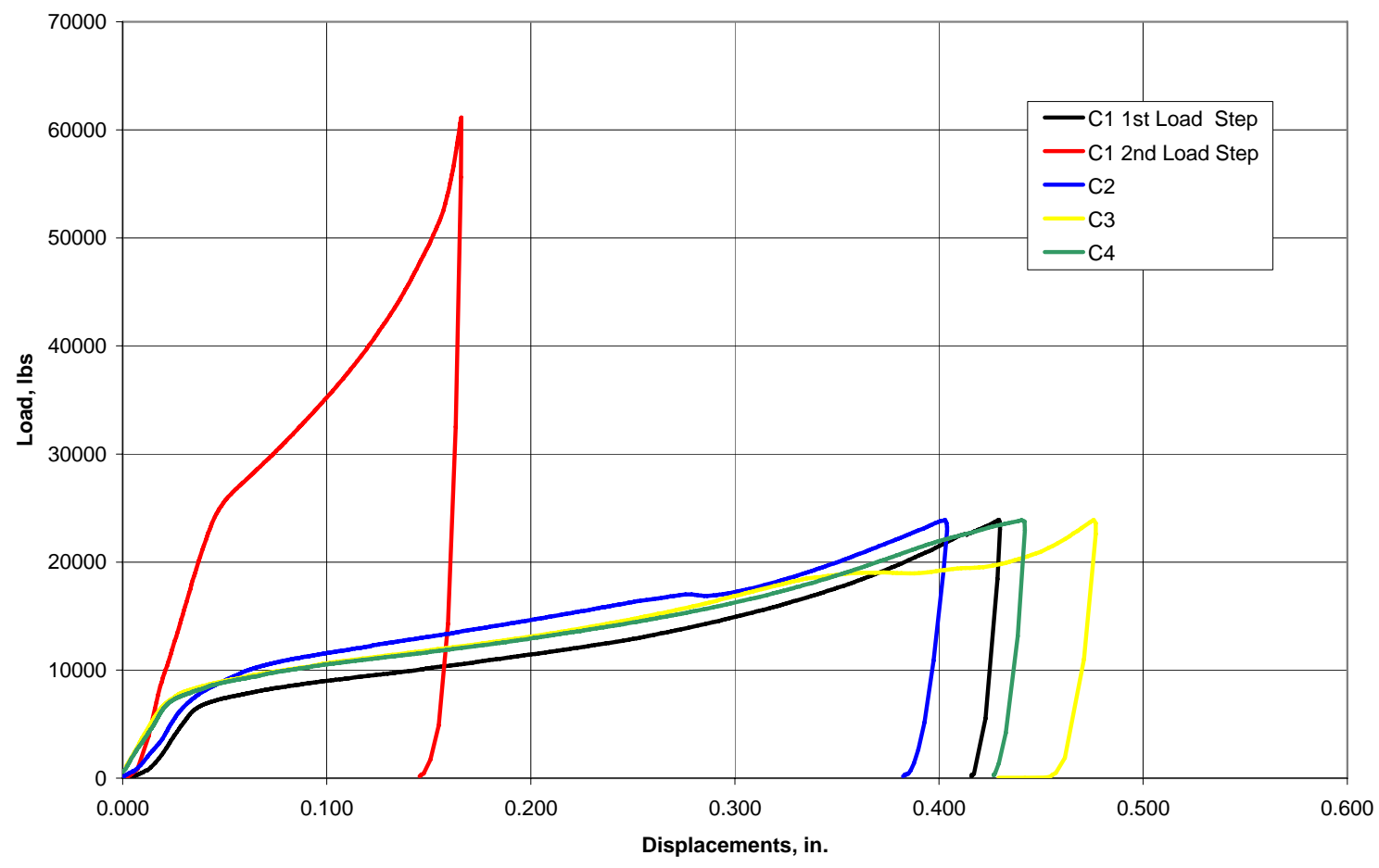

Figure 4.7: Crush test load displacement curves. 


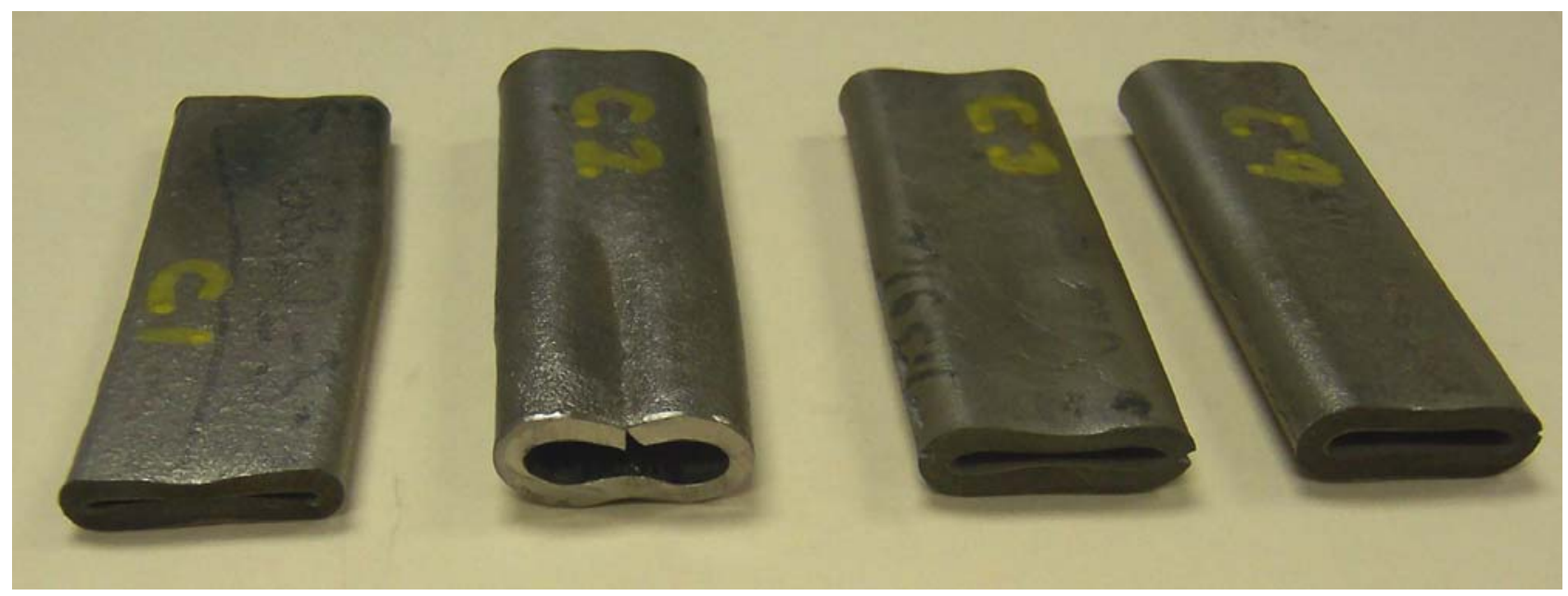

Figure 4.8: Crush test samples after the test, Sample C1 (left) did not crack. Samples C2, C3, and C4 (right) cracked.

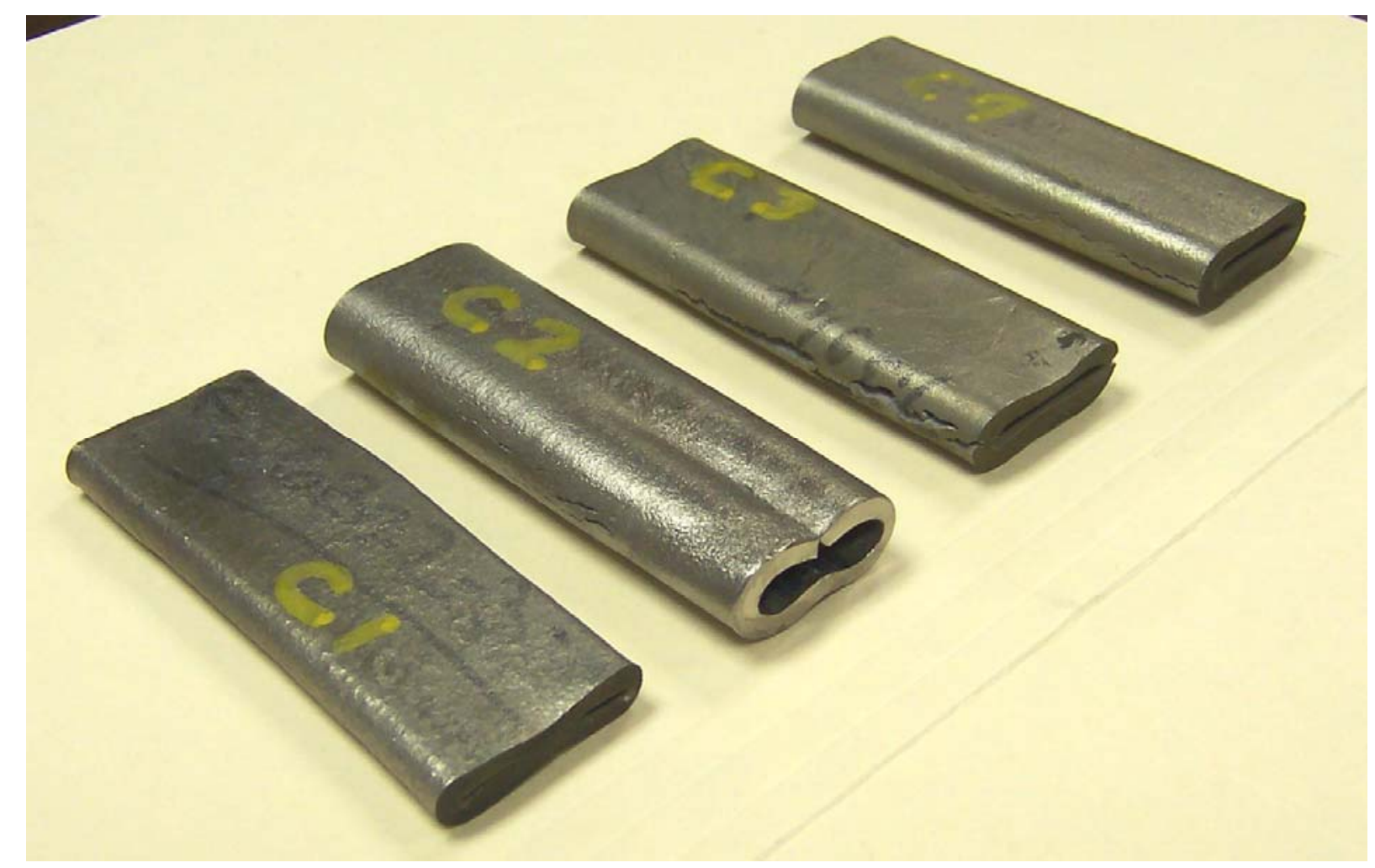

Figure 4.9: Crush test samples after the test, Sample C1 (left) did not crack. Samples C2, C3, and C4 (right) cracked. 


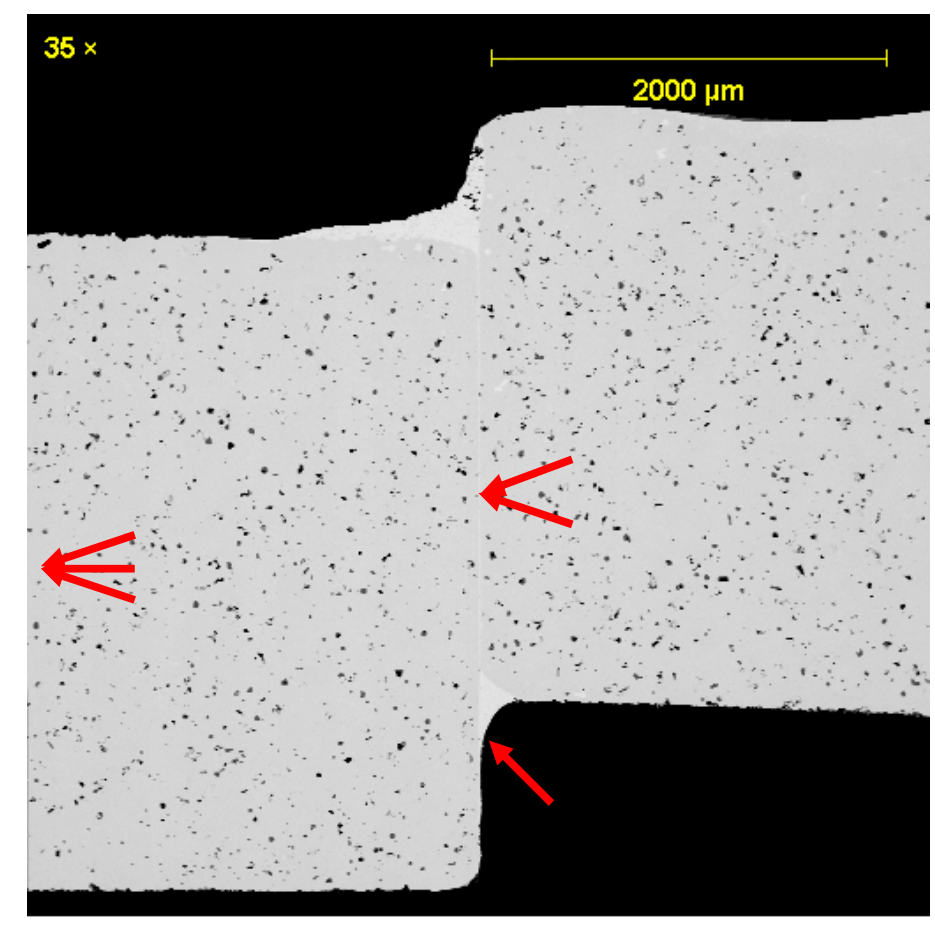

A. A cross-section through the joint in sample 2.

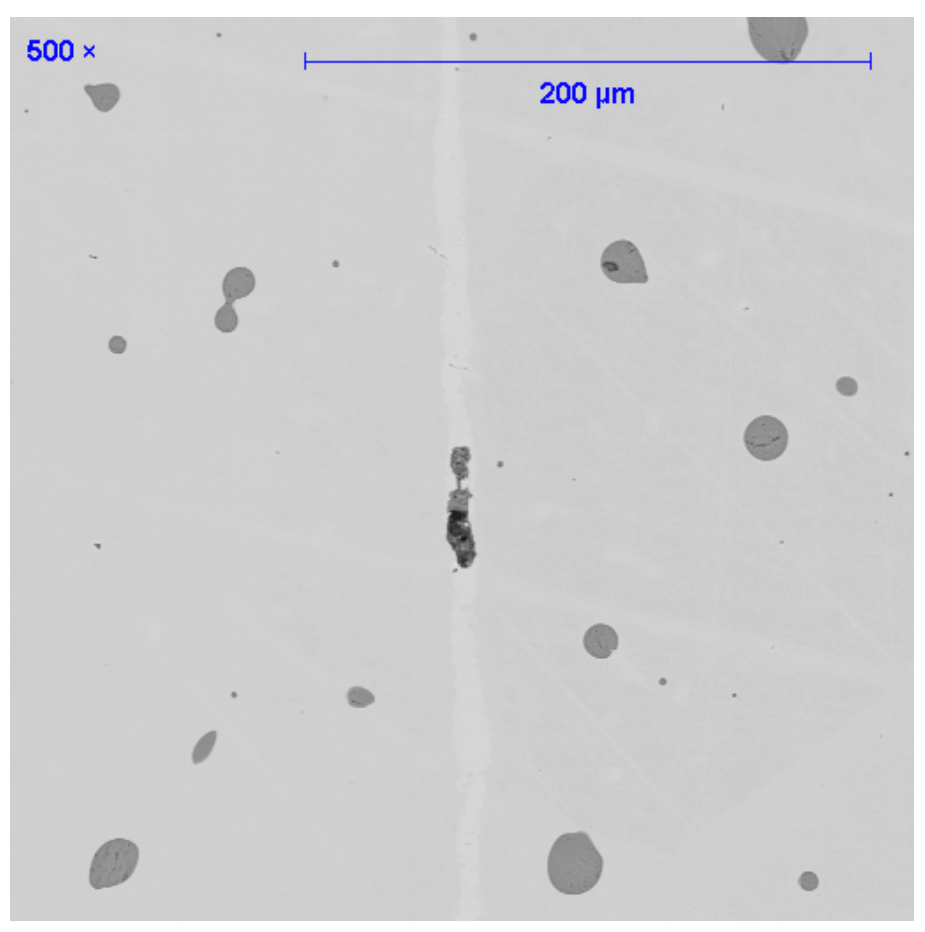

B. A close up view of the braze joint in sample 1.

Figure 4.10: Microhardness photographs. 


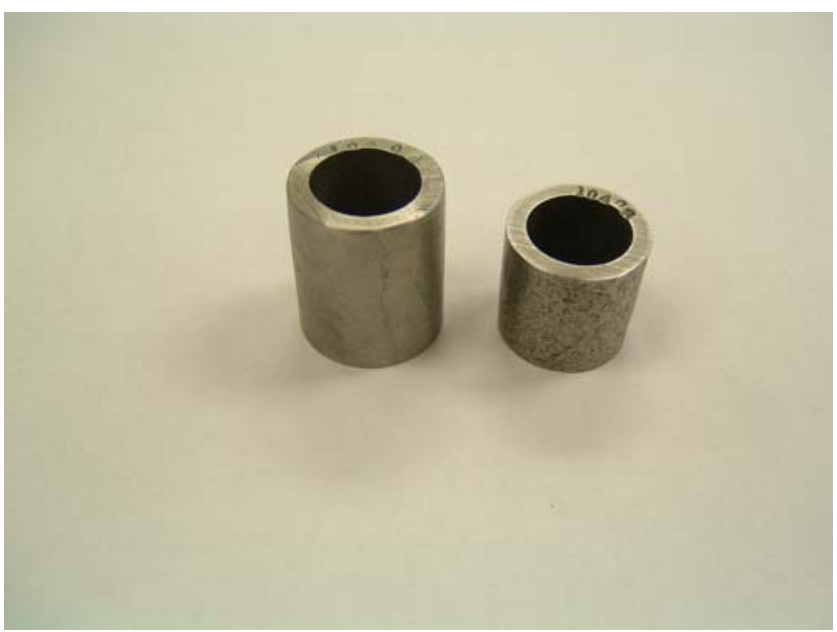

Figure 4.11: Samples used for corrosion tests.

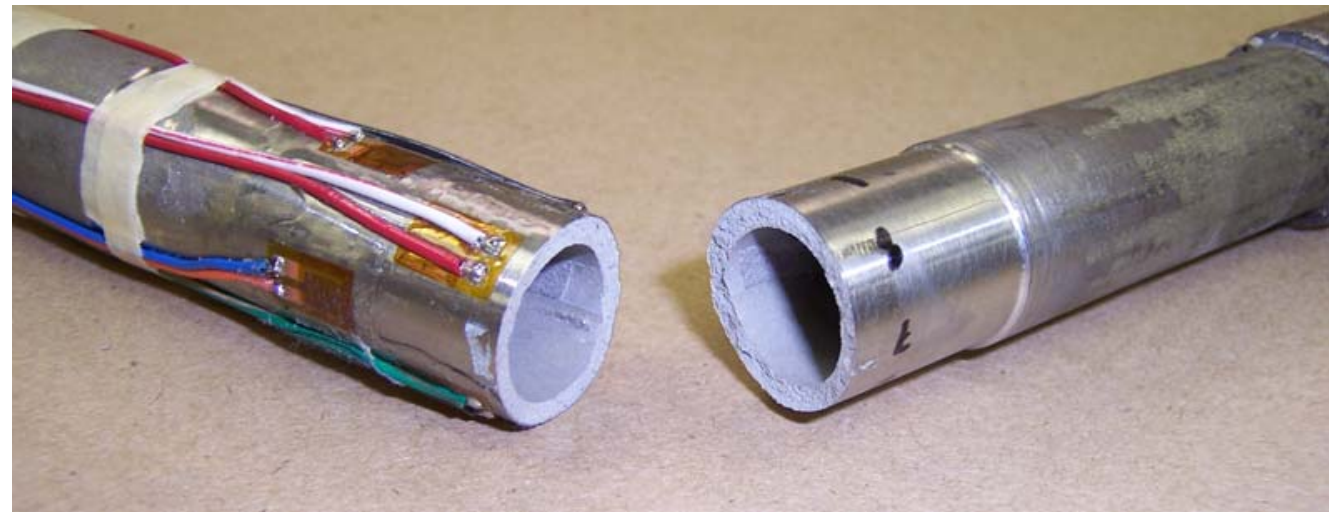

Figure 4.12: Fatigue failure surfaces ( 0.9 ” from right edge of turned down region)

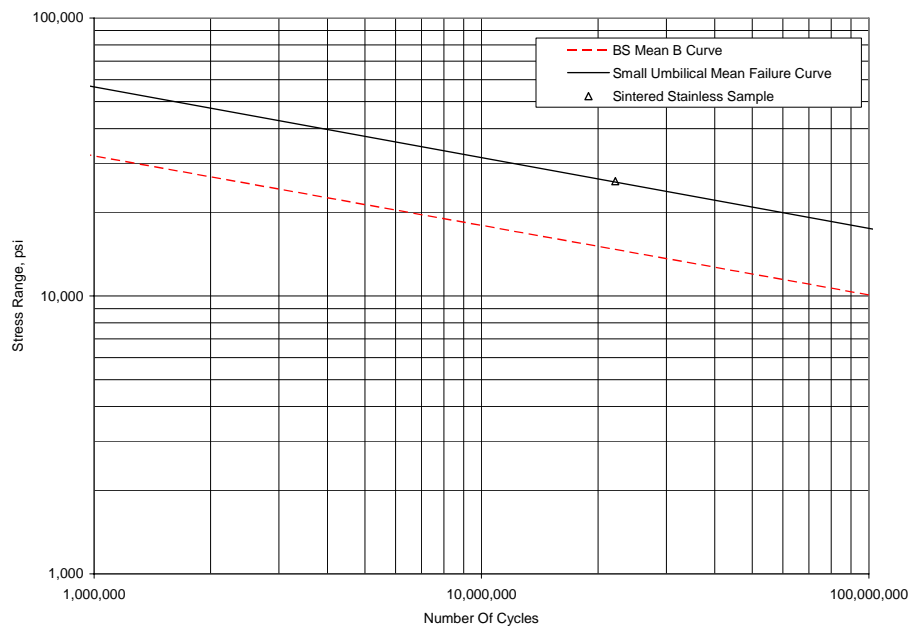

Figure 4.13: Sintered stainless tube fatigue results. 
TABLE 4.1

Fatigue test strain ranges

\begin{tabular}{|c|c|c|c|c|c|c|c|c|c|c|c|c|c|}
\hline \multirow[t]{2}{*}{ Sample } & & \multicolumn{10}{|c|}{ Strain Range, ue } & \multirow{2}{*}{$\begin{array}{l}\text { Max.Stress } \\
\text { Range, psi }\end{array}$} & \multirow[t]{2}{*}{ Cycles } \\
\hline & & SG 1 & SG 2 & SG 3 & SG 4 & SG 5 & SG 6 & SG 7 & SG 8 & Average & Maximum & & \\
\hline & 1 & 308 & 335 & 340 & 292 & 297 & 378 & 399 & 347 & 337 & $\begin{array}{r}399 \\
\end{array}$ & 11,983 & 965,121 \\
\hline & 2 & 740 & 728 & 765 & 747 & 718 & 793 & 863 & 860 & 777 & 863 & 25,902 & $9,638,313$ \\
\hline & 3 & - & - & - & - & - & 1554 & - & 1567 & 1560 & 1567 & 47,003 & $1,151,242$ \\
\hline
\end{tabular}

TABLE 4.2

$\mathrm{N}=\mathrm{A}\left(\mathrm{S}^{\wedge}-\mathrm{m}\right)$ Basic form of the S-N curve

$\mathrm{S}=$ stress range, mpa

$\mathrm{m}=\quad-4$ slope of "B'" curve

$\mathrm{n}=\quad 1$ number of failures

A "B" desigt $1.01 \mathrm{E}+15$ for the "B" Design Curve used to calculate Damage

$\mathrm{SCF}=\quad 1$ Equivalent Connector Stress Concentration Factor (adjust to A survival above A design)

\begin{tabular}{|c|c|c|c|r|r|r|r|r|r|r|r|r|r|}
\hline \multirow{3}{*}{ Sample } & \multicolumn{3}{|c|}{ 1st Test } & \multicolumn{3}{|c|}{ 2nd Test } & \multicolumn{3}{c|}{ 3rd Test } & $\begin{array}{c}\text { Total } \\
\text { Damage }\end{array}$ & $\begin{array}{c}\text { Equivalent } \\
\text { Stress Range } \\
\text { mpa }\end{array}$ & $\begin{array}{c}\text { Equivalent } \\
\text { Stress Range } \\
\text { psi }\end{array}$ & $\begin{array}{c}\text { Equivalent } \\
\text { Test Duration } \\
\text { Cycles }\end{array}$ \\
\hline \hline 1 & 11983 & 965,121 & 0.0445 & 25902 & $9,638,313$ & 9.7047 & 47003 & $1,151,242$ & 12.5705 & 22.3197 & 178.58 & 25893.68 & $22,166,982$ \\
\hline
\end{tabular}




\section{CONCLUSIONS AND RECOMMENDATIONS}

- It is possible to sinter in microwave continuously steel tubular products. However, since the sintering temperature window is quite narrow, the scale-up process therefore has to be developed very carefully.

- $\quad$ Cost per foot to process Microwave Tubing would be difficult to estimate at this time due to lack of enough available processing data and a prototype microwave sintering system.

- Some mechanical properties of the microwave processed tubes were better than the existing tubular, and some were just marginally better or a little inferior.

- $\quad$ Scale up and sintering of a thin wall common O.D. size tubing that is widely used in the market is still to be proved

- Further experimentation and refinement of the sintering process is needed to entice industry commitment, for example:

- $\quad$ Improved material characteristics would likely be required

- Improved consistency of material characteristics

- Actual manufacturing capability of microwave sintered, industrial quality, full length tubing will most likely require several million dollars of investment. 